\title{
Sustainable energy-water management for residential houses with optimal integrated grey and rain water recycling
}

\author{
Evan Wanjiru*, Xiaohua Xia \\ Centre of New Energy Systems, Department of Electrical, Electronic and Computer Engineering, University of \\ Pretoria, Pretoria 0002, South Africa
}

\begin{abstract}
South Africa is a semi-arid developing country facing water and energy insecurity. There are colossal challenges in reliably providing these resources amid growing population, increased urbanization and improved living standards causing increased demand for these resources. Development of new supply centralized systems comes at an exorbitant cost, whereas decentralized systems are touted as an attractive alternative. Grey water recycling and rain water harvesting at buildings level is such an alternative that can provide water for non-potable uses. However, there are technological challenges of optimally operating such systems while ensuring efficient use of associated energy. This paper introduces two control strategies; open loop optimal control and closed-loop model predictive control (MPC) strategies aimed at ensuring safe and reliable operation of the grey water recycling and rain water harvesting system while efficiently using associated energy. From the case study, the proposed system with either control strategy can save the cost of water and waste water by up to $32.3 \%$ and $29.5 \%$ respectively, while leading to $35.7 \%$ in energy cost savings and $31.5 \%$ in total operational cost savings in a month. Adoption of these systems would have a huge environmental effect in reducing demand for sewerage services, conservation of water hence reducing demand for potable water as well as increasing the energy efficiency. Furthermore, the system would increase the reliability and security of water supply. Despite the benefits, the system does not pay within its lifetime and therefore, government intervention is required so as to make it economically attractive. High cost of implementation coupled with low potable and waste water tariffs harbour adoption of these systems. Appropriate regulations, policies, incentives and public education are necessary to support such novel technologies in ensuring resource conservation, efficiency and security are achieved.
\end{abstract}

Keywords: demand side management; energy-water nexus; grey water; life cycle cost analysis; optimal control; rain water harvesting

\begin{tabular}{|l|}
\hline Nomenclature \\
$A_{t}^{1}, A_{t}^{2}, A_{t}^{3} \quad$ Cross-sectional area of potable, grey and holding water tank $\left(\mathrm{m}^{2}\right)$ respectively
\end{tabular}

*Corresponding author. Tel. +27 12420 6767; Fax +27 123625000 .

Email address: murimev@gmail.com (Evan Wanjiru ) 


\begin{tabular}{|ll|}
\hline$D_{\text {grey }}, D_{\text {pot }}$ & Potable and grey water demand $\left(\mathrm{m}^{3}\right)$ respectively \\
$h_{1}, h_{2}, h_{3}$ & Height of water in potable, grey and holding tank $(\mathrm{m})$ respectively \\
$p_{e}$ & Price of electricity using TOU tariff $($ currency $/ \mathrm{kWh})$ \\
$P_{1}^{m}, P_{3}^{m}$ & Potable and grey water pump's motor rating $(\mathrm{kW})$ respectively \\
$s_{1}, s_{3}$ & Auxiliary variable for potable and grey water pump respectively \\
$S_{\text {grey }}, S_{\text {rain }}$ & Collected untreated grey and rain water respectively $\left(\mathrm{m}^{3}\right)$ \\
TOU & Time-of-use tariff \\
$t_{s}$ and $j$ & Sampling period $(h)$ and $j^{t h}$ sampling interval \\
$u_{1}, u_{2}$ & Potable water pump's switch and valve respectively \\
$u_{3}, u_{4}$ & Grey water pump's switch and drainage valve respectively \\
$Q_{1}, Q_{3}$ & Flow rate of water across potable and grey water pump $\left(\mathrm{m}^{3} / \mathrm{h}\right)$ respectively \\
$Q_{2}, Q_{4}$ & Flow rate of water across potable and drainage valve $\left(\mathrm{m}^{3} / \mathrm{h}\right)$ respectively \\
$V_{1}, V_{2}, V_{3}$ & Volume of water in respective tanks ( $\left.\mathrm{m}^{3}\right)$ \\
& \\
Rand $(\mathrm{R})$ & South African currency (1 Rand $=0.076 \mathrm{USD}$, as at $17 \mathrm{Aug} .2017)$ \\
\hline
\end{tabular}

\section{Introduction}

Most developing nations are struggling to provide water and energy, two resources that are greatly connected, hence the name energy-water nexus (Wanjiru et al. (2017a)). In South Africa, various factors such as economic growth, improved standards of living, population increase, ruralurban migration, frequent droughts, greater connectivity, insufficient and seasonal rainfall have increased the insecurity of the two resources (Odhiambo (2009); Cobbinah et al. (2015)). The country suffered from serious power shortages in 2008 that necessitated authorities to come up with various initiatives to improve the situation. According to Xia and Zhang (2016), supply side initiatives such as building of new coal power plants were not only harmful to the environment but they also came at exorbitant cost. On the other hand, demand side management (DSM) initiatives that bridge the gap between supply and demand were more desirable, encironmentally friendly and cheaper to implement. Consequently, energy DSM research across various sectors has successfully been carried out. In commercial and industrial sectors, energy DSM initiatives include energy efficiency in coal plants through optimal sizing and operation of pumps studied by Zhang et al. (2014), while Badenhorst et al. (2011) looked at scheduling of deep mine rock winders, Numbi and Xia (2016) analysed optimal energy control of coal crushers and Chatterjee et al. (2015) looked into optimally operating of ventilation systems with the aim of managing energy consumption. Others like Mathaba and Xia (2015) explored energy management of conveyor belts, water pumping stations (Zhang et al. (2012)), including those with multiple pumps (Zhuan and Xia (2013)). Optimal dynamic power dispatch by utilities has been studied by Elaiw et al. (2012) with the aim of limiting emissions, while Chou and Xia (2007) investigated on efficient and optimal operation of heavy haul trains. Application of renewable energy as a suitable alternative source of clean energy has also been examined. A minimum cost solution model for photovoltaic-diesel-battery power systems was designed by Tazvinga et al. (2013) to provide optimal power flow for remote customers, and later extended to cater for distributed energy systems 
(Tazvinga et al. (2015)). Further, Tazvinga et al. (2014) have proposed an energy dispatch strategy for photovoltaic-wind-diesel-battery power system. In residential buildings, Malatji et al. (2013) examined an optimal energy-efficient building retrofitting decision model whereas Wang et al. (2014) considered life cycle cost analysis and retrofitting planning in their model and Fan and Xia (2017) developed an optimization model for building envelope retrofitting planning. Setlhaolo and Xia (2015) have delved in demand response research involving optimal scheduling of household appliances. Energy management in hot water supply has been studied by Ntsaluba et al. (2016) who looked into optimal operation of a solar water heating systems, whilst Sichilalu et al. (2017) examined suitability of heat pump water heaters powered by remote hybrid energy systems as well as grid-tied systems (Sichilalu and Xia (2015)).

South Africa has a constant water stress of about $40 \%$ to $60 \%$ resulting from low amount of rainfall averaging at about $500 \mathrm{~mm}$ per annum (Roy and Rouault (2013)), and high evaporation of about $1700 \mathrm{~mm}$ per annum (Adewumi et al. (2010)). Just like energy, water management can be carried out on supply or demand side. With extraction of fresh water sources nearing yield point, development of new centralized water supply and sewage disposal systems comes at astronomical costs, negative environmental impact and is also incompatible with modern complex requirements, especially in developing cities. The solution has been in development of cheaper decentralized systems that minimize the amount of pollution generated and discharged through using and reusing water very near to the point of origin. Decentralized systems, as pointed out by Wanjiru and Xia (2017), have further been supported by technological advancement in water treatment technologies, change of attitude and awareness on the importance of water conservation. Water insecurity is forcing municipalities to explore alternative means of supplying and managing water consumption. They include water restrictions, pressure management (Hoy (2009)), monitoring water consumption pattern, management of meters, installation and retrofitting with efficient devices, planting of water efficient vegetation (Adewumi et al. (2010)), communication and education (Bohensky (2006)), and promotion of waste water reuse (Lam et al. (2015)). Evidently, as Brandoni and Bošnjaković (2017) elaborate, most DSM initiatives have exclusively focused on either energy or water despite them being heavily intertwined both in production and consumption levels. In fact, decisions made on one resource have been shown to have undesired effect on the other since decision makers have little understanding on scientific or policy complexities of one resource on the other (Stillwell et al. (2010)). It is therefore important to consider energy-water nexus DSM in order to bridge the gap between supply and demand through conservation and efficient utilisation of both resources. This nexus has been appreciated well in developed countries, while developing countries are still catching up, with South Africa leading in the research in Africa. A number of energy-water DSM research in residential buildings in the country have been carried out. Wanjiru et al. (2016a) developed an open-loop optimal controller to operate heat pump water heaters and instantaneous heaters powered using integrated renewable energy systems for off-grid and later expanded for grid tied application (Wanjiru et al. (2017c)), as well as control using closed-loop model predictive control (MPC) (Wanjiru et al. (2017b)). The studies sought maximize the use of renewable energy while minimizing the amount of cold water wasted at end uses. In another study, Wanjiru and Xia (2015) explored harvesting rooftop rain water and optimizing the operation of autonomous lawn irrigation. For buildings with intermittent or insufficient water supply that rely on pump-storage systems, Wanjiru et al. (2016b) examined the 
optimal operation of the system using both open-loop optimal and MPC controllers. Further, the two controllers have been designed for grey water recycling system by Wanjiru and Xia (2017) suitable for urban residential buildings with the aim of minimizing the amount of pumping energy used as well as ensure conservation of potable water takes place.

Grey water is the waste water generated from households that has no faecal matter, for instance, water from washing machines, shower, baths and dishwasher. This water is easier to treat as it contains fewer pathogens, to be reused on-site for non-potable uses such as lawn irrigation and toilet flushing. Domestic grey water recycling and rain water harvesting systems not only have environmental benefits but also economic benefits to end users and the country at large. Most research has mainly focused on separate rain water harvesting systems. For instance, Kahinda and Taigbenu (2011) higlight the challenges and opportunities of rain water harvesting in South Africa while Morales-Pinzón et al. (2015) look at their economic and environmental benefits. Al-Jayyousi (2003) review the suitability of grey water recycling systems to achieve sustainable water management. However, Kim et al.(2007) argue that combined grey and rain water recycling systems could have more benefits than exclusive water recycling systems, though, the analysis done by Stec et al. (2017) shows that financial efficiency on water and energy savings would vary with the size of the system and region. Ghisi and de Oliveira (2007) looked into the potential of grey water recycling and rain water harvesting system in Brazil. First, the performance and payback period of the grey water and rain water harvesting systems was analysed separately, and later, the combined grey and rain water system's performance was analysed. It was found out that though the three systems have huge potential in conserving water, they had a high payback period of more than 20 years. Another study in Beijing by Zhang et al. (2009) revealed that grey water recycling is more suitable in the area than rain water harvesting due to severe pollution in the city that could reduce the quality of rain water. A localized water recycling and rain water harvesting scheme was designed by Rozos et al. (2009) and the analysis showed that although both rain water harvesting and grey water recycling lead to water conservation, schemes based on recycling grey water are less susceptible to climatic changes, while those based on rain water harvesting are more susceptible to changes. Therefore, a combined grey water recycling and rain water harvesting is suitable for a country like South Africa with low rainfall, in order to achieve maximum benefits and reliability. Three land uses, that is, single-family house, apartment cluster and mixed use site, were analysed for viability of use of grey water recycling and rain water harvesting systems as an alternative source of water supply for non-potable uses. Though water is conserved in all the three uses, the largest impediment to their adoption is cost. In fact, Loux et al. (2012) assert that the cost is much higher for single-family house, while the discrepancy between cost and savings levels out at higher densities. Despite the important benefits that such systems have on the environment and utilities, there are still technological challenges on their optimal operation so as to ensure both water and energy efficiency are achieved. In existing systems, some operations have to be carried out manually by home owners. Solutions to these challenges must be provided in consideration of energy-water nexus so as to maximize the combined results from the system.

Previous research has focused on designing grey and rain water systems, with little attention being given to optimal, reliable and autonomous operation of such systems. Various control strategies can be used to operate as well as minimize the system's dependence on human operator. Classical control techniques such as proportional-integral-derivative (PID) controllers use a 
trial and error process where various methods are iteratively used to determine design variables of an acceptable system. PID controllers, according to Kozák (2016), are suitable for single-inputsingle-output (SISO) applications and have low accuracy in non-linear processes, or those with a large time delay. Constrained direct inversion (CDI) controllers are superior to conventional control strategies with feedback loop as they can handle disturbances, constraints, dead time and non-linearity. Optimal control, whether open-loop or closed-loop model predictive control (MPC), seeks to determine the control actions that will operate a process within physical and operational constraints while simultaneously minimizing or maximizing a given performance criteria online (Kirk (2012)). Though CDI uses an analytical approach while optimal control uses numeric optimization, they at times offer similar results. This makes CDI to be more computationally efficient than MPC hence suitable for simple control systems. Optimal controllers, on the other hand, perform better in reaching optimality as CDI's rule is not designed to be optimal (Tóth et al. (2012)). Optimal controllers can effectively, robustly and accurately handle multi-variable dynamic systems through minimizing the cost function (Mayne et al. (2000)). The aim of this research, therefore, is to develop suitable optimal controllers that can reliably, autonomously and robustly control the water recycling system while considering energy-water nexus to maximize the benefits.

This paper introduces the first attempt to design novel, economical and advanced optimal controllers to operate the grey and rain water recycling system for residential areas. Open-loop optimal control and closed-loop MPC systems are designed to meet hourly potable and non-potable water demand for a house leading to water conservation and energy efficiency. The control strategies are designed to cater for different application requirements. Although open-loop control is more cost effective and easy to implement, it is suitable where water demand is known to be relatively uniform. However, in cases where it is difficult to accurately predict water demand and the system is susceptible to external disturbances that significantly affect the demand pattern, the closed-loop MPC should be adopted. It, however, requires installation of additional monitoring devices to the system such as level monitoring of the tanks thereby increasing the cost and complexity of the control system. The proposed system, if widely adopted, would reduce the demand for potable water, energy and sewage services from the utilities and municipalities, leading to lower cost of potable and waste water which corresponds to lower bills paid by the end user associated to both resources. However, it is important for subsidies and rebates to be offered by the government to lower the cost of implementing such systems in individual houses.

This paper is outlined as follows: Section 2 shows how the model for the proposed grey water recycling and rain water harvesting is developed. Section 3 discusses the design of the controllers, Section 4 provides information about the case used to test the control systems and other information necessary for implementing the proposed strategy. Section 5 discusses the results while Section 6 gives the conclusion and recommendations.

\section{System development}

\subsection{Schematic layout}

A typical grey and rain water water recycling system for a stand alone house is shown in Figure 1. Two scenarios motivated by the water situation in South Africa are considered. Firstly, the house is considered to have reliable municipal water supply such that pumping and storage is 


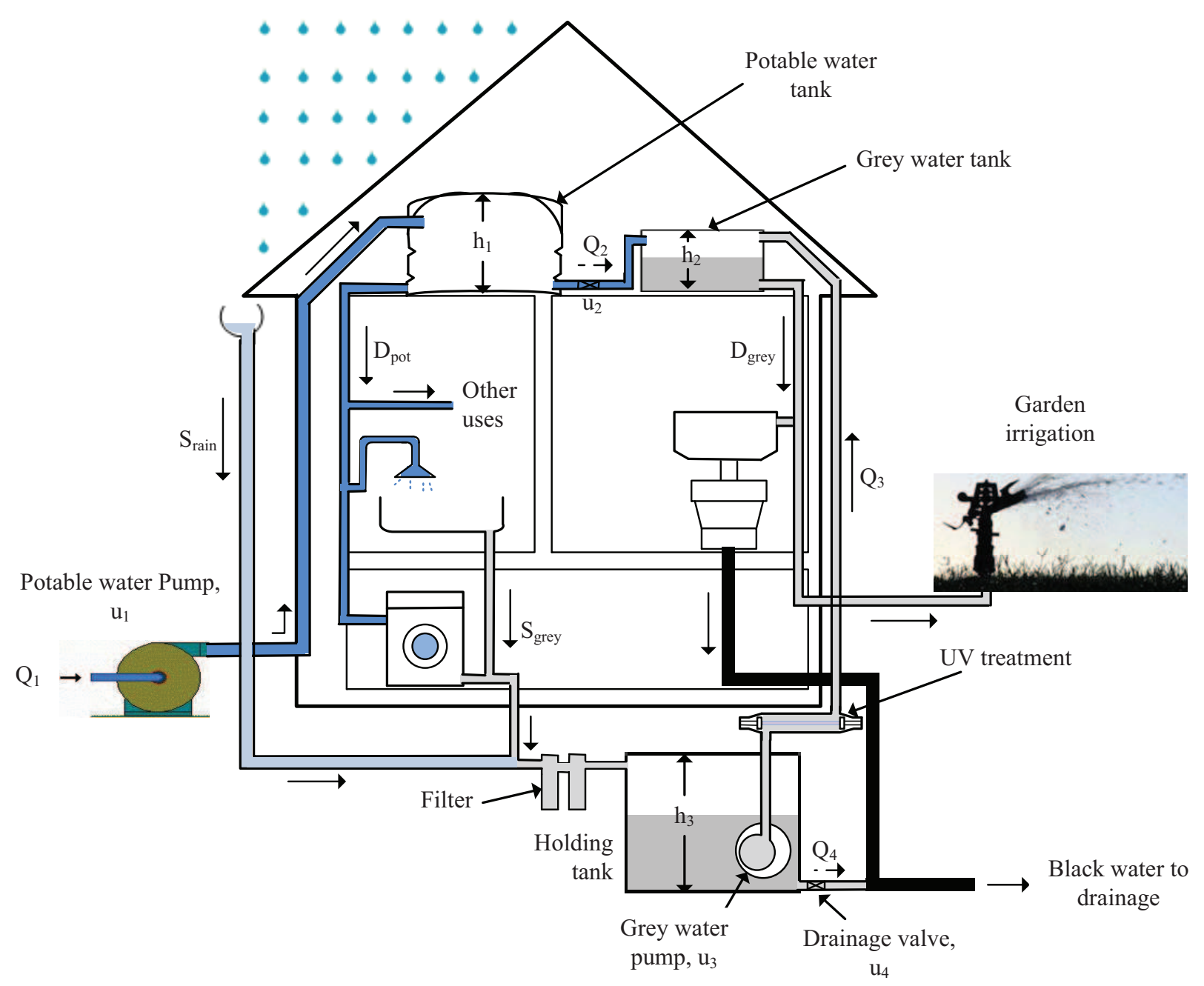

Figure 1: Schematic of grey and rain water water recycling system.

not required as water flows to various end uses in the house and through valve $u_{2}$ when necessary. Secondly, water supply is unreliable, either because of low water pressure or water rationing taking place in the area. Therefore, water pumping and storage is necessary to improve the reliability and convenience of potable water supply to the house occupants. A fixed speed potable water pump whose state is represented as $u_{1}$ pumps water to the potable storage water tank from where it flows by gravity to various end uses in the house. Some end uses such as shower and washing machine produce grey water that can easily be treated for non-potable end uses such as toilet and garden irrigation. Further, rain water can also be harvested from the roof and used for the same non-potable end uses. Recycling grey water and harvesting rain water would lead to water conservation as well as reducing demand for potable water and sewage services in both scenarios. Both grey and rain water pass through a filter to remove particles and then flows to the holding tank for temporary storage. This tank must be emptied, through the drainage valve represented as $u_{4}$, every 24 -h to prevent formation of bacteria responsible for producing foul smell. Collected 
grey water is then pumped through an ultraviolet (UV) water purifier and stored in a rooftop grey water tank, from where it flows by gravity to non-potable end uses. In instances where grey water tank has insufficient treated water, potable water is allowed to flow through potable water valve $u_{2}$ to assist in meeting the demand. Finally, black water, which cannot easily be recycled, is allowed to flow to the drainage. Therefore, the aim is to control pumps and valves to ensure convenient and reliable water supply that ensures both energy-water efficiency and conservation are achieved.

\subsection{Potable water tank}

In the scenario where municipal water supply is reliable, potable water tank is not required. On the contrary, if municipal water supply is unreliable, water has to be pumped by potable water pump into the potable water tank for storage, where it flows by gravity to various end uses. Assuming that all tanks in this study have uniform cross-sectional area, the volume of water in this tank, $V_{1}\left(m^{3}\right)$, can be modelled as,

$$
\dot{V}_{1}=A_{1}^{t} \dot{h}_{1}=Q_{1} u_{1}-Q_{2} u_{2}-\dot{D}_{\text {pot }},
$$

where $A_{1}^{t}$ is the cross-sectional area of the tank $\left(\mathrm{m}^{2}\right)$ while $h_{1}$ is the height of water in the tank $(m)$. $D_{\text {pot }}$ is the potable water demand $\left(\mathrm{m}^{3}\right)$ in the house while $Q_{1}$ and $Q_{2}$ are the flow rates $\left(\mathrm{m}^{3} / \mathrm{h}\right)$ of potable water pump and solenoid valve respectively. Differential equation (1) can be expressed in discrete-time domain by a first order difference equation as follows;

$$
h_{1}(j+1)=h_{1}(j)+\frac{1}{A_{1}^{t}}\left[t_{s} Q_{1} u_{1}(j)-t_{s} Q_{2} u_{2}(j)-D_{p o t}(j)\right],
$$

where $j$ the sampling interval and $t_{s}$ is the sampling period during a full operating cycle of 24-h. Level sensors are economical and easy to use in measuring the volume of water in tanks with uniform cross-sectional area (Lipták (2005)). Therefore, equation (2) can be modelled in terms of the water level in a sampling interval, $h_{1}(j)$, which the controller would use to convert to volume. Through recurrence manipulation, the equation becomes,

$$
h_{1}(j)=h_{1}(0)+\frac{t_{s}}{A_{1}^{t}} \sum_{i=1}^{j}\left[Q_{1} u_{1}(i)-Q_{2} u_{2}(i)\right]-\frac{1}{A_{1}^{t}} \sum_{i=1}^{j} D_{p o t}(i) \quad 1 \leq j \leq N,
$$

where $N$ is the total number of cycles during the full 24-h operating cycle, obtained as $N=\frac{24}{t_{s}}$.

\subsection{Grey water tank}

Treated grey water is stored in this tank for future use by non-potable water end uses. If the tank has no water, potable water is allowed into this tank through valve $u_{2}$ and then flows to meet the required demand. Therefore, volume, $V_{2}\left(\mathrm{~m}^{3}\right)$, of water in this tank is,

$$
\dot{V}_{2}=A_{2}^{t} \dot{h}_{2}=Q_{2} u_{2}+Q_{3} u_{3}-\dot{D}_{\text {grey }},
$$

where $A_{2}^{t}$ is the cross-sectional area $\left(m^{2}\right)$ of the tank, $h_{2}$ is the height of water $(m)$ in the tank, $D_{\text {grey }}$ is the grey water demand $\left(\mathrm{m}^{3}\right)$ while $Q_{3}$ is the water flow rate $\left(\mathrm{m}^{3} / \mathrm{h}\right)$ through the grey water pump. Expressing equation (4) in discrete-time domain yields,

$$
h_{2}(j+1)=h_{2}(j)+\frac{1}{A_{2}^{t}}\left[t_{s} Q_{2} u_{2}(j)+t_{s} Q_{3} u_{3}(j)-D_{\text {grey }}(j)\right],
$$


which can further be expressed as

$$
h_{2}(j)=h_{2}(0)+\frac{t_{s}}{A_{2}^{t}} \sum_{i=1}^{j}\left[Q_{2} u_{2}(i)+Q_{3} u_{3}(i)\right]-\frac{1}{A_{2}^{t}} \sum_{i=1}^{j} D_{\text {grey }}(i) \quad 1 \leq j \leq N .
$$

\subsection{Holding tank}

Untreated grey and rain water flows through filters to remove physical impurities to temporary storage in the holding tank. Whenever treated grey water is required in the grey water tank, the collected water is pumped by grey water pump through the UV purifier. It is important to empty the holding tank every 24 hours to prevent formation of bacteria that cause foul smell. Consequently, the volume, $V_{3}\left(\mathrm{~m}^{3}\right)$, of water in this tank can be modelled as,

$$
\dot{V}_{3}=A_{3}^{t} \dot{h}_{3}=\dot{S}_{\text {grey }}+\dot{S}_{\text {rain }}-Q_{3} u_{3}-Q_{4} u_{4},
$$

where $A_{3}^{t}$ is the cross-sectional area $\left(\mathrm{m}^{2}\right)$ of the tank, $h_{3}$ is the height $(m)$ of water in the tank. $S_{\text {grey }}$ and $S_{\text {rain }}$ are the volume $\left(\mathrm{m}^{3}\right)$ of water supplied from the recyclable potable water end uses and rain water harvesting respectively, while $Q_{4}$ is the flow rate $\left(\mathrm{m}^{3} / \mathrm{h}\right)$ of untreated grey water through the drainage valve. Expressing equation (7) in discrete-time domain leads to,

$$
h_{3}(j+1)=h_{3}(j)+\frac{1}{A_{3}^{t}}\left[S_{\text {grey }}(j)+S_{\text {rain }}(j)-t_{s} Q_{3} u_{3}(j)-t_{s} Q_{4} u_{4}(j)\right] \text {, }
$$

which transforms to,

$$
h_{3}(j)=h_{3}(0)+\frac{1}{A_{3}^{t}} \sum_{i=1}^{j}\left[S_{\text {grey }}(i)+S_{\text {rain }}(i)\right]-\frac{t_{s}}{A_{3}^{t}} \sum_{i=1}^{j}\left[Q_{3} u_{3}(i)+Q_{4} u_{4}(i)\right] \quad 1 \leq j \leq N .
$$

Dynamic equations (3), (6) and (9) are used in designing the two controllers that optimally operate the proposed grey and rain water recycling system.

\section{Controller design}

In this study, two model based controllers that use advanced optimal control concept are designed. The controllers seek to minimize cost of pumping energy of potable and collected grey water, minimize consumption of potable water in the house and finally maximize the life of these pumps through minimizing the maintenance cost normally represented as the number of times a pump is switched on and off during the operating cycle.

\subsection{Open-loop optimal controller}

The open-loop optimal controller uses the feed forward principle in that hourly water demand in the house is measured prior to running the controller. This demand pattern is used by the controller to predict the future behaviour of the system throughout the full operating cycle. As 
previously stated, the open-loop controller seeks to minimize the cost of pumping energy, consumption of potable water in the house and maximize the life of the pumps. These performance indicators can be modelled to form the following objective function,

$$
J=\sum_{j=1}^{N}\left[\alpha_{1} t_{s} p_{e}(j) P_{1}^{m} u_{1}(j)+\alpha_{2} t_{s} Q_{2} u_{2}(j)+\alpha_{3} t_{s} p_{e}(j) P_{3}^{m} u_{3}(j)\right]+\alpha_{4} \sum_{j=1}^{N}\left[s_{1}(j)+s_{3}(j)\right],
$$

where $P_{1}^{m}(k W)$ and $P_{3}^{m}(k W)$ are potable and grey water power pump's power consumption respectively, while $p_{e}$ and $t_{s}$ are cost of electricity using the TOU tariff during the $j^{\text {th }}$ sampling interval and the sampling time respectively. $s_{1}(j)$ and $s_{3}(j)$ are auxiliary variables used to minimize the switching frequency of potable and grey water pumps respectively. Mathaba et al. (2014) show that each auxiliary variable is represented by a value 1 whenever a pump's state changes from off to on. Weights $\alpha_{1}$ to $\alpha_{4}$ are used to tune the controller according to user's preference. First and third terms in equation (10) minimize the cost of energy consumed by the pumps, the second term minimizes the consumption of potable water by grey water end uses while the fourth term is responsible for minimizing the switching frequency the two pumps.

Every system functions within certain physical and operational constraints for safe and reliable operation. Constraints present in this system are mathematically modelled as follows;

$$
\begin{aligned}
& h_{1}^{\min } \leq h_{1}(j) \leq h_{1}^{\max }, \\
& h_{2}^{\min } \leq h_{2}(j) \leq h_{2}^{\max }, \\
& h_{3}^{\min } \leq h_{3}(j) \leq h_{3}^{\max }, \\
& h_{3}(N)=h_{3}^{f}, \\
& u_{1}(1)-s_{1}(1) \leq 0, \\
& u_{1}(j)-u_{1}(j-1)-s_{1}(j) \leq 0, \\
& u_{3}(1)-s_{3}(1) \leq 0, \\
& u_{3}(j)-u_{3}(j-1)-s_{3}(j) \leq 0, \\
& u_{m}(j) \in\{0,1\} \text { where } m=1,2,3,4, \\
& s_{1}(j), s_{3}(j) \in\{0,1\} .
\end{aligned}
$$

Various tank capacities are the physical constraints while emptying of the holding tank and switching frequency of the pumps are the main operational constraints affecting the system. Therefore, the tanks are modelled in inequalities (11), (12) and (13) to have the level of water maintained between set minimum and maximum levels. Potable and grey water tanks should never be emptied whereas the holding tank must be emptied within the $24-\mathrm{h}$ operating cycle. This is given by equation $(14)$, where $h_{3}^{f}$ is the final water level in the tank. Inequalities (15) and (17) initialize the auxiliary variables as the initial state of the respective $u$ while inequalities (16) and (18) favour the control that involves less switching frequency of the respective pumps. Finally equations (19) and (20) are bounds for the control variables that is, the status of the pumps and switches as well as the auxiliary variables respectively. 


\subsubsection{Open-loop control algorithm}

The objective function and constraints are solved using the canonical form presented by Numbi and Xia (2015);

$$
\min f^{T} X
$$

subject to

$$
\left\{\begin{array}{l}
A X \leq b \text { (linear inequality constraint) } \\
A_{e q} X=b_{e q} \text { (linear equality constraint) } \\
L_{B} \leq X \leq U_{B} \text { (lower and upper bounds). }
\end{array}\right.
$$

Here, vector $X$ consists of all the control variables in the optimization problem, that is,

$$
\begin{array}{r}
X=\left[u_{1}(1), \ldots, u_{1}(N), u_{2}(1) \ldots, u_{2}(N), u_{3}(1), \ldots, u_{3}(N), u_{4}(1), \ldots, u_{4}(N),\right. \\
\left.s_{1}(1), \ldots, s_{1}(N), s_{3}(1), \ldots, s_{3}(N)\right]_{6 N \times 1}^{T},
\end{array}
$$

while elements of vector $f^{T}$ are obtained from objective function $(10)$ as,

$$
\begin{array}{r}
f^{T}=\left[\alpha_{1} t_{s} P_{1}^{m} p_{e}(1), \ldots, \alpha_{1} t_{s} P_{1}^{m} p_{e}(N), \alpha_{2} t_{s} Q_{2} \ldots, \alpha_{2} t_{s} Q_{2}, \alpha_{3} t_{s} P_{3}^{m} p_{e}(1), \ldots, \alpha_{3} t_{s} P_{3}^{m} p_{e}(N),\right. \\
\left.0, \ldots, 0, \alpha_{4}, \ldots, \alpha_{4}, \alpha_{4}, \ldots, \alpha_{4}\right]_{1 \times 6 N} .
\end{array}
$$

Since there are several linear inequalities, each is modelled separately and later combined into the canonical linear inequality form $(A X \leq b)$. First, linear inequality constraint (11) is modelled to,

$$
\begin{aligned}
A_{1} X & \leq b_{1}, \\
-A_{1} X & \leq b_{2},
\end{aligned}
$$

where

$$
\begin{gathered}
A_{1}=\left[\begin{array}{cccccccccccc}
-Q_{1} t_{s} & 0 & \ldots & 0 & Q_{2} t_{s} & 0 & \ldots & 0 & 0 & \ldots & \ldots & 0 \\
-Q_{1} t_{s} & -Q_{1} t_{s} & \ldots & 0 & Q_{2} t_{s} & Q_{2} t_{s} & \ldots & 0 & 0 & \ldots & \ldots & 0 \\
\vdots & \vdots & \ddots & \vdots & \vdots & \vdots & \ddots & \vdots & \vdots & \ddots & \ddots & \vdots \\
-Q_{1} t_{s} & -Q_{1} t_{s} & \ldots & -Q_{1} t_{s} & Q_{2} t_{s} & Q_{2} t_{s} & \ldots & Q_{2} t_{s} & 0 & \ldots & \ldots & 0
\end{array}\right]_{N \times 6 N} \\
b_{1}=\left[\begin{array}{c}
-D_{p o t}(1)-A_{1}^{t}\left\{h_{1}^{\min }-h_{1}(0)\right\} \\
-\left\{D_{p o t}(1)+D_{p o t}(2)\right\}-A_{1}^{t}\left\{h_{1}^{\min }-h_{1}(0)\right\} \\
\vdots \\
-\left\{D_{p o t}(1)+\ldots+D_{p o t}(N)\right\}-A_{1}^{t}\left\{h_{1}^{\min }-h_{1}(0)\right\}
\end{array}\right]_{N \times 1}
\end{gathered}
$$

and

$$
b_{2}=\left[\begin{array}{c}
D_{p o t}(1)+A_{1}^{t}\left\{h_{1}^{\max }-h_{1}(0)\right\} \\
\left\{D_{p o t}(1)+D_{p o t}(2)\right\}+A_{1}^{t}\left\{h_{1}^{\max }-h_{1}(0)\right\} \\
\vdots \\
\left\{D_{p o t}(1)+\ldots+D_{p o t}(N)\right\}+A_{1}^{t}\left\{h_{1}^{\max }-h_{1}(0)\right\}
\end{array}\right]_{N \times 1}
$$


Then, inequality constraint (12) becomes,

$$
\begin{array}{r}
A_{2} X \leq b_{3}, \\
-A_{2} X \leq b_{4},
\end{array}
$$

where

$$
\begin{gathered}
A_{2}=\left[\begin{array}{ccccccccccccccc}
0 & \ldots & 0 & -Q_{2} t_{s} & 0 & \ldots & 0 & -Q_{3} t_{s} & 0 & \ldots & 0 & 0 & \ldots & \ldots & 0 \\
0 & \ldots & 0 & -Q_{2} t_{s} & -Q_{2} t_{s} & \ldots & 0 & -Q_{3} t_{s} & -Q_{3} t_{s} & \ldots & 0 & 0 & \ldots & \ldots & 0 \\
\vdots & \ddots & \vdots & \vdots & \vdots & \ddots & \vdots & \vdots & \vdots & \ddots & \vdots & \vdots & \ddots & \ddots & \vdots \\
0 & \ldots & 0 & -Q_{2} t_{s} & -Q_{2} t_{s} & \ldots & -Q_{2} t_{s} & -Q_{3} t_{s} & -Q_{3} t_{s} & \ldots & -Q_{3} t_{s} & 0 & \ldots & \ldots & 0
\end{array}\right], \\
b_{3}=\left[\begin{array}{c}
-D_{\text {grey }}(1)-A_{2}^{t}\left\{h_{2}^{\text {min }}-h_{2}(0)\right\} \\
-\left\{D_{\text {grey }}(1)+D_{\text {grey }}(2)\right\}-A_{2}^{t}\left\{h_{2}^{\text {min }}-h_{2}(0)\right\} \\
\vdots \\
-\left\{D_{\text {grey }}(1)+\ldots+D_{\text {grey }}(N)\right\}-A_{2}^{t}\left\{h_{2}^{\text {min }}-h_{2}(0)\right\}
\end{array}\right]
\end{gathered}
$$

and

$$
b_{4}=\left[\begin{array}{c}
D_{\text {grey }}(1)+A_{2}^{t}\left\{h_{2}^{\max }-h_{2}(0)\right\} \\
\left\{D_{\text {grey }}(1)+D_{\text {grey }}(2)\right\}+A_{2}^{t}\left\{h_{2}^{\max }-h_{2}(0)\right\} \\
\vdots \\
\left\{D_{\text {grey }}(1)+\ldots+D_{\text {grey }}(N)\right\}+A_{2}^{t}\left\{h_{2}^{\max }-h_{2}(0)\right\}
\end{array}\right]
$$

while inequality (13) can be remodelled to,

$$
\begin{aligned}
A_{3} X & \leq b_{5}, \\
-A_{3} X & \leq b_{6},
\end{aligned}
$$

where

$$
\begin{gathered}
A_{3}=\left[\begin{array}{cccccccccccccccc}
0 & \ldots & \ldots & 0 & Q_{3} t_{s} & 0 & \ldots & 0 & Q_{4} t_{s} & 0 & \ldots & 0 & 0 & \ldots & \ldots & 0 \\
0 & \ldots & \ldots & 0 & Q_{3} t_{s} & Q_{3} t_{s} & \ldots & 0 & Q_{4} t_{s} & Q_{4} t_{s} & \ldots & 0 & 0 & \ldots & \ldots & 0 \\
\vdots & \ddots & \ddots & \vdots & \vdots & \vdots & \ddots & \vdots & \vdots & \vdots & \ddots & \vdots & \vdots & \ddots & \ddots & \vdots \\
0 & \ldots & \ldots & 0 & Q_{3} t_{s} & Q_{3} t_{s} & \ldots & Q_{3} t_{s} & Q_{4} t_{s} & Q_{4} t_{s} & \ldots & Q_{4} t_{s} & 0 & \ldots & \ldots & 0
\end{array}\right], \\
b_{5}=\left[\begin{array}{c}
\left\{S_{\text {grey }}(1)+S_{\text {rain }}(1)-A_{3}^{t}\left\{h_{3}^{\text {min }}-h_{3}(0)\right\}\right. \\
\vdots \\
\left\{S_{\text {grey }}(1)+S_{\text {grey }}(2)+S_{\text {rain }}(1)+S_{\text {rain }}(2)\right\}-A_{3}^{t}\left\{h_{3}^{\text {min }}-h_{3}(0)\right\} \\
\vdots \\
\left\{\begin{array}{c}
\text { grey } \\
\text { grain }
\end{array}(1)+\ldots+S_{\text {rain }}(N)\right\}-A_{3}^{t}\left\{h_{3}^{\text {min }}-h_{3}(0)\right\}
\end{array}\right]
\end{gathered}
$$

and

$$
b_{6}=\left[\begin{array}{c}
-\left\{S_{\text {grey }}(1)+S_{\text {rain }}(1)\right\}+A_{3}^{t}\left\{h_{3}^{\max }-h_{3}(0)\right\} \\
-\left\{S_{\text {grey }}(1)+S_{\text {grey }}(2)+S_{\text {rain }}(1)+S_{\text {rain }}(2)\right\}+A_{3}^{t}\left\{h_{3}^{\max }-h_{3}(0)\right\} \\
\vdots \\
\left.-\ldots S_{\text {grey }}(1)+\ldots+S_{\text {grey }}(N)+S_{\text {rain }}(1)+\ldots+S_{\text {rain }}(N)\right\}+A_{3}^{t}\left\{h_{3}^{\text {max }}-h_{3}(0)\right\}
\end{array}\right]
$$


Lastly, auxiliary variables in inequalities $(15)-(18)$ are remodelled as

$$
A_{4} X \leq b_{7},
$$

where

$$
\begin{aligned}
& A_{4}= \\
& {\left[\begin{array}{ccccc:cc:ccccc:cc:cccc:cccc}
1 & 0 & \ldots & 0 & 0 & 0 \ldots & \ldots & 1 & 0 & \ldots & 0 & 0 & 0 \ldots & -1 & 0 & \ldots & 0 & -1 & 0 & \ldots & 0 \\
-1 & 1 & \ldots & 0 & 0 & 0 \ldots & \ldots & -1 & 1 & \ldots & 0 & 0 & 0 & 0 & 0 & -1 & \ldots & 0 & 0 & -1 & \ldots & 0 \\
\vdots & \vdots & \ddots & \vdots & \vdots & \vdots & \vdots & \vdots & \vdots & \ddots & \vdots & \vdots & \vdots & \ddots & \vdots & \vdots & \ddots & \vdots & \vdots & \vdots & \ddots & \vdots \\
0 & 0 & \ldots & -1 & 1 & 0 \ldots & 0 & 0 & \ldots & -1 & 1 & 0 \ldots & 0 & 0 & \ldots & -1 & 0 & 0 & \ldots & -1
\end{array}\right]}
\end{aligned}
$$

and

$$
b_{7}=\left[\begin{array}{lll}
0 & \ldots & 0
\end{array}\right]^{T} .
$$

Matrices $A_{1}$ to $A_{4}$ have $(N \times 6 N)$ dimension while vectors $b_{1}$ to $b_{7}$ have a dimension of $(N \times 1)$. Therefore, linear inequality in the canonical form (22) becomes,

$$
A=\left[\begin{array}{c}
A_{1} \\
-A_{1} \\
A_{2} \\
-A_{2} \\
A_{3} \\
-A_{3} \\
A_{4}
\end{array}\right]_{7 N \times 6 N} \quad b=\left[\begin{array}{l}
b_{1} \\
b_{2} \\
b_{3} \\
b_{4} \\
b_{5} \\
b_{6} \\
b_{7}
\end{array}\right]_{7 N \times 1} .
$$

In the same degree, linear equality constraint (14) becomes,

$$
A_{e q} X=b_{e q},
$$

where

$$
A_{e q}=\left[\begin{array}{ccc:cccccc:ccc}
0 & \ldots & 0 & 0 & \ldots & 0 & 0 & \ldots & 0 & 0 & \ldots & 0 \\
\vdots & \ddots & \vdots & \vdots & \ddots & \vdots & \vdots & \ddots & \vdots & \vdots & \ddots & \vdots \\
0 & \ldots & 0 & 0 & \ldots & 0 & 0 & \ldots & 0 & 0 & \ldots & 0 \\
0 & \ldots & 0 & Q_{3} t_{s} & \ldots & Q_{3} t_{s} & Q_{4} t_{s} & \ldots & Q_{4} t_{s} & 0 & \ldots & 0
\end{array}\right]_{N \times 6 N}
$$

and

$$
b_{e q}=\left[\begin{array}{c}
0 \\
\vdots \\
0 \\
A_{3}^{t}\left\{h_{3}(0)-h_{3}^{f}\right\}+\left\{S_{\text {grey }}(1)+\ldots+S_{g} \operatorname{rey}(N)+S_{\text {rain }}(1)+\ldots+S_{\text {rain }}(N)\right\}
\end{array}\right]_{N \times 1},
$$

while the bounds given in equations (19) and (20) become,

$$
L_{B}=\left[\begin{array}{lll}
0 & \ldots & 0
\end{array}\right]_{6 N \times 1}^{T} \quad \text { and } \quad U_{B}=\left[\begin{array}{lll}
1 & \ldots & 1
\end{array}\right]_{6 N \times 1}^{T} .
$$

This binary integer optimization problem is solved using the SCIP solver in OPTI toolbox, a free Matlab optimization toolbox. This solver is indicated as the fastest non-commercial optimization solver by Setlhaolo and Xia (2016). 


\subsection{Closed-loop MPC control}

Closed-loop model predictive control (MPC) has the ability to predict the future behaviour of the system, cope with constraints in the design process and robustly deal with disturbances present in the system. MPC makes use of both feed forward and feed back measurements from the system to compute the control law on-line (Mayne et al. (2000)). As discussed by Wang (2009), it obtains the current control response by solving an open-loop optimal control optimization problem using the current state of the plant as the initial state in each sampling time. From the optimal sequence generated, only the first control is implemented. The state of the plant (water level in the tanks) is measured. During the next iteration, $\mathrm{k}+1$, objective function and constraints are updated while taking the previous state of the tanks (water level at sampling time $k$ ) as the initial state. The process of optimization is carried out in real time over the new control horizon $\left(N_{c}=N-k+1\right)$ to give the receding horizon control law. This process is repeated throughout the entire operating cycle (Xia and Zhang (2015)).

The objective function, $J_{m p c}$, can be derived from the open-loop objective (10) as,

$$
\begin{aligned}
J_{m p c}= & \sum_{j=k}^{k+N_{c}-1}\left[\alpha_{1} t_{s} p_{e}(j) P_{1}^{m} u_{1}(j \mid k)+\alpha_{2} t_{s} Q_{2} u_{2}(j \mid k)+\alpha_{3} t_{s} p_{e}(j) P_{3}^{m} u_{3}(j \mid k)\right] \\
& +\alpha_{4} \sum_{j=k}^{k+N_{c}-1}\left[s_{1}(j \mid k)+s_{3}(j \mid k)\right],
\end{aligned}
$$

where $N_{c}$ is the control horizon, $u_{1}(j \mid k), u_{2}(j \mid k)$ and $u_{3}(j \mid k)$ are optimized control actions while $s_{1}(j \mid k)$ and $s_{3}(j \mid k)$ are auxiliary values at $j^{\text {th }}$ sampling interval based on most recent measurements carried out at time $k$. Although MPC problems normally have predicting, $N_{p}$, and control, $N_{c}$, horizons, only the control horizon, $N_{c}$, is included in this optimization problem since none of the state variables (height of water in the tank) is present in the objective function. Therefore, the control horizon can be given as

$$
N_{c}=N-k+1 .
$$

State equations are modified from equations (3), (6) and (9) to,

$$
\begin{array}{r}
h_{1}(j \mid k)=h_{1}(k)+\frac{t_{s}}{A_{1}^{t}} \sum_{i=k}^{j}\left[Q_{1} u_{1}(i \mid k)-Q_{2} u_{2}(i \mid k)\right]-\frac{1}{A_{1}^{t}} \sum_{i=k}^{j} D_{\text {pot }}(i), \\
h_{2}(j \mid k)=h_{2}(k)+\frac{t_{s}}{A_{2}^{t}} \sum_{i=k}^{j}\left[Q_{2} u_{2}(i \mid k)+Q_{3} u_{3}(i \mid k)\right]-\frac{1}{A_{2}^{t}} \sum_{i=k}^{j} D_{\text {grey }}(i), \\
h_{3}(j \mid k)=h_{3}(k)+\frac{1}{A_{3}^{t}} \sum_{i=k}^{j}\left[S_{\text {grey }}(i)+S_{\text {rain }}(i)\right]-\frac{t_{s}}{A_{3}^{t}} \sum_{i=k}^{j}\left[Q_{3} u_{3}(i \mid k)+Q_{4} u_{4}(i \mid k)\right], \\
k \leq j \leq k+N_{c}-1,
\end{array}
$$

where $h_{1}(j \mid k), h_{2}(j \mid k)$, and $h_{3}(j \mid k)$ are predicted levels of water in the respective tanks at $j^{\text {th }}$ sampling interval based on information available at time $k$. Moreover, the system experiences the same 
physical and operational constraints as the open-loop control system. With feedback of water level measurements in various tanks at every iteration, constraints and equations (11)-(20), are modified to,

$$
\begin{aligned}
h_{1}^{\text {min }} & \leq h_{1}(j \mid k) \leq h_{1}^{\text {max }}, \\
h_{2}^{\text {min }} & \leq h_{2}(j \mid k) \leq h_{2}^{\text {max }}, \\
h_{3}^{\text {min }} & \leq h_{3}(j \mid k) \leq h_{3}^{\text {max }}, \\
h_{3}(N) & =h_{3}^{f}, \\
u_{1}(1 \mid k) & -s_{1}(1 \mid k) \leq 0, \\
u_{1}(j \mid k) & -u_{1}(j-1 \mid k)-s_{1}(j \mid k) \leq 0, \\
u_{3}(1 \mid k) & -s_{3}(1 \mid k) \leq 0, \\
u_{3}(j \mid k) & -u_{3}(j-1 \mid k)-s_{3}(j \mid k) \leq 0, \\
u_{m, c}(j \mid k) & \in\{0,1\} \text { where } m=1,2,3,4, \\
s_{1}(j \mid k), s_{3}(j \mid k) & \in\{0,1\} .
\end{aligned}
$$

\subsubsection{MPC algorithm}

Similar to the open-loop control algorithm, control vector, represented as $X_{m p c}$, contains the control variables such that,

$$
\begin{aligned}
& X_{m p c}= \\
& \quad\left[u_{1}(k \mid k), u_{1}(k+1 \mid k), \ldots, u_{1}\left(k+N_{c}-1 \mid k\right)\right), u_{2}(k \mid k), u_{2}(k+1 \mid k), \ldots, u_{2}\left(k+N_{c}-1 \mid k\right), \\
& \left.u_{3}(k \mid k), u_{3}(k+1 \mid k), \ldots, u_{3}\left(k+N_{c}-1 \mid k\right)\right), u_{4}(k \mid k), u_{4}(k+1 \mid k), \ldots, u_{4}\left(k+N_{c}-1 \mid k\right), \\
& \left.\quad s_{1}(k \mid k), s_{1}(k+1 \mid k), \ldots, s_{1}\left(k+N_{c}-1 \mid k\right), s_{3}(k \mid k), s_{3}(k+1 \mid k), \ldots, s_{3}\left(k+N_{c}-1 \mid k\right)\right]_{6 N \times 1}^{T} .
\end{aligned}
$$

Zhang and Xia (2011) describe the work flow of the MPC controller as follows;

1. For time, $k$, find the control horizon $\left(N_{c}(k)\right)$ using equation (46).

2. Optimization: Find the optimal solution within the control horizon;

minimize objective function (45),

subject to constraints 50$)-(59)$.

3. From the optimal solution, implement $\left[u_{1}(k \mid k), u_{2}(k \mid k), u_{3}(k \mid k), u_{4}(k \mid k)\right]^{T}$ to the plant.

4. Feed back: Measure state variables $h_{1}(k+1), h_{2}(k+1)$ and $h_{3}(k+1)$.

5. Set $k=k+1$ and update system states and inputs and outputs.

6. Repeat steps 1-5 until $k$ reaches a predefined value.

This binary integer optimization problem solved using the SCIP solver in OPTI toolbox. 


\section{Pertinent information}

\subsection{Case study}

A building in Pretoria, South Africa, has unreliable water supply forcing occupants to pump and store water in a rooftop storage tank, from where it flows by gravity to all end uses. Consumption of potable water and associated energy is used as the baseline for this study. The $0.8 \mathrm{~kW}$ fixed speed pump with a flow rate of $0.9 \mathrm{~m}^{3} / \mathrm{h}$ is controlled by level switches that just detect empty and full levels. Whenever the tank is empty, water is pumped until the tank is full, regardless of TOU period. End uses in the house were identified and some had their hourly water use measured using digital flow meters and data loggers while others were estimated after interviewing the occupants. These end uses were categorized as those that must use potable water, those that could use treated grey water and those whose used water is suitable for recycling. The hourly water demand for a typical week day and a weekend in this house is shown in Figure 2. It can be seen from the curves

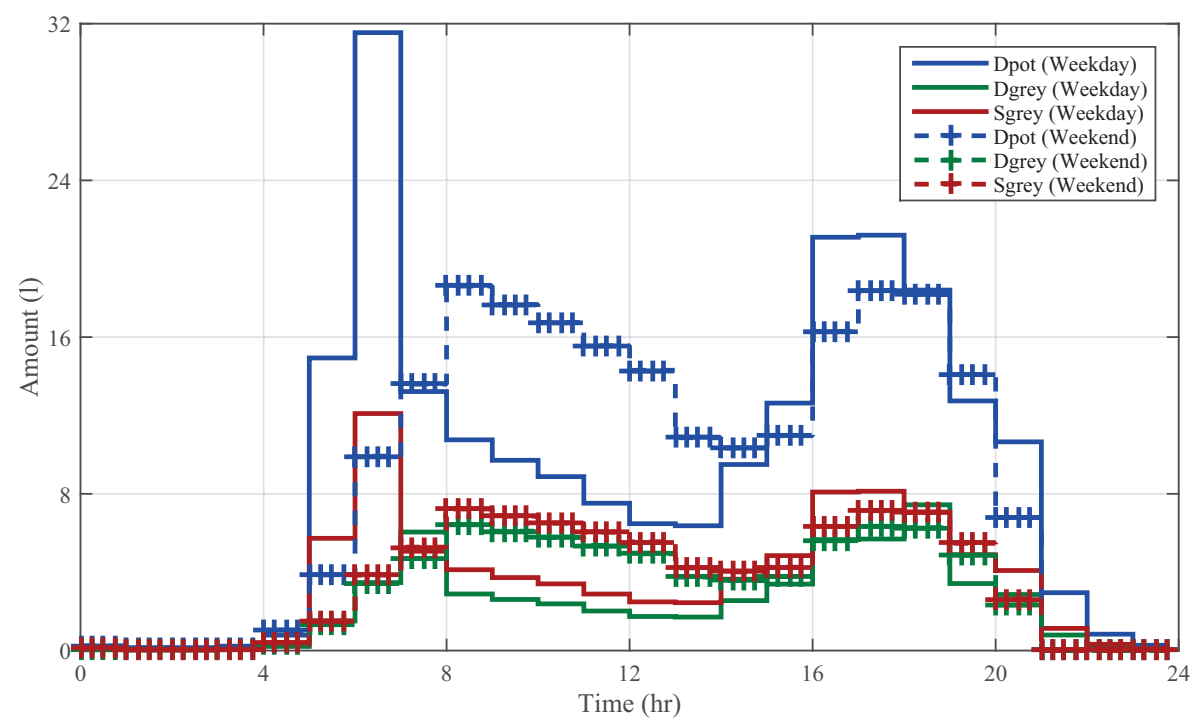

Figure 2: Hourly water profile for a typical week day and weekend.

that the grey water supply, $S_{\text {grey }}$, is always less than the potable water demand, $D_{\text {pot }}$, as some of this potable water qualifies to be recycled. On the contrary, the grey water demand, $D_{\text {grey }}$, doesn't necessarily follow the others, as this demand entirely depends on the human behaviour.

The current cylindrical potable water tank has the dimensions given in Table 1 . In order to incorporate grey and rain water recycling, two tanks; grey and holding water tanks are required. Typical dimensions and capacity constraints of these tanks are given in Table 1. Level sensors will be used monitor the water level between minimum and maximum levels given in Table 1. This is to ensure safe and reliable operation of the system by avoiding either running the tanks completely empty or spilling the water hence damaging the roof of the house. The grey water pump to be incorporated would be rated at $650 \mathrm{~W}$ with flow rate of $0.35 \mathrm{~m}^{3} / \mathrm{h}$.

To enable rain water harvesting, about $50 \mathrm{~m}^{2}$ of the house's roof can easily have rain water directed to the holding tank, through the filters. The area's weather data, that includes the hourly 
Table 1: Dimensions and capacity of the tanks.

\begin{tabular}{lcccc}
\hline Tank & Radius $(\mathrm{m})$ & Height $(\mathrm{m})$ & Min & Max \\
\hline Potable & 0.55 & 1.2 & 0.1 & 1.0 \\
Grey & 0.36 & 1.0 & 0.1 & 0.8 \\
Holding & 0.30 & 0.6 & 0 & 0.5 \\
\hline
\end{tabular}

amount of rainfall, is obtained from the Southern African Universities Radiometric Network 1 , University of Pretoria's station.

\subsection{Time-of-use electricity tariff}

Time-of-use (TOU) tariff, commonly used across the world to encourage shifting of peak load, and Middelberg et al.(2009) show that it can vary by time of day, day of week and season. Eskom's TOU Homeflex ${ }^{2}$ structure for residential consumers given below is used.

$$
p_{e}(t)=\left\{\begin{array}{l}
p_{\text {off }}=0.5510 \quad R / K w h \quad \text { if } t \in[0,6] \cup[10,18] \cup[20,24] \\
p_{\text {peak }}=1.748 \quad R / K w h \quad \text { if } t \in[7,10] \cup[18,20]
\end{array}\right.
$$

where $p_{o f f}$ is the off peak price, $p_{\text {peak }}$ is the peak time price, $R$ is the South African currency, Rand, and $t$ is the time of day in hours.

\subsection{Potable and waste water tariffs}

Table 2 shows the water and waste water tariffs for domestic consumers in the City of Tshwane The amount of waste water discharged into the drainage system is calculated as a percentage of the

Table 2: City of Tshwane tariff for 2014/2015

\begin{tabular}{lcccccccc}
\hline Water $\left(\mathrm{m}^{3} /\right.$ month $)$ & $0-6$ & $7-12$ & $13-18$ & $19-24$ & $25-30$ & $31-42$ & $43-72$ & $>72$ \\
Price $\left(R / \mathrm{m}^{3}\right)$ & 6.81 & 9.72 & 12.77 & 14.77 & 16.89 & 18.25 & 19.53 & 20.91 \\
Discharge $(\% /$ month $)$ & 98 & 90 & 75 & 60 & 52 & 10 & 1 & 1 \\
Price $\left(R / m^{3}\right)$ & 5.06 & 6.83 & 8.81 & 8.81 & 8.81 & 8.81 & 8.81 & 8.81 \\
\hline
\end{tabular}

amount of potable water consumed in a household per month. Since potable and waste water are charged through an incremental block tariff, it is important to carry out simulations over a month in order to obtain the cost incurred by the end user. It is assumed that the demand pattern repeats itself over the 24-h operating cycle, for weekdays and the two days of the week end. In this study, the weekday water demand profile, $D_{\text {pot }}$ (weekday), is assumed to be the same for all the 5 week days. Similarly, the weekend demand profile, $D_{\text {pot }}$ (weekend), is also taken to be the same for the 2 days of the weekend. Therefore, both open-loop and closed-loop control systems are run over the 24 -h operating cycle and then repeated over a month. The month is taken to have 4 complete

\footnotetext{
http://www.sauran.net

2 http://www.eskom.co.za/

3 wWw.tshwane.gov.za
} 
weeks with each week having 5 weekdays and 2 days of the weekend. Taking the first day of the month to be a Monday, the cumulative volume of potable water consumed up to a certain weekday, $D_{p o t, w k d y}$, or a weekend, $D_{p o t, w k n d}$, is obtained as;

$$
\begin{aligned}
& D_{p o t, w k d y}=(5 q) D_{p o t}(\text { weekday })+(2 q-2) D_{p o t}(\text { weekend }), \\
& D_{p o t, w k n d}=(5 q) D_{p o t}(\text { weekday })+(2 q-1) D_{p o t}(\text { weekend }),
\end{aligned}
$$

where $q$ is the number of the week in the month $(q=1,2,3,4)$. This amount is then used to compute the amount of waste water discharged and eventually the cost of potable and waste water in a month.

\section{Analysis of optimal results}

The two control strategies are verified using the case study in section 4.1. Simulations are carried out for an operating cycle of 24-h with a sampling period, $t_{s}=15$ minutes. The legend showing peak and off peak periods of the TOU electricity tariff (section 4.2) is used throughout the paper. Moreover, only potable and grey water pumps, whose status are represented by $u_{1}$ and $u_{3}$ respectively, are considered to consume power hence subjected to the TOU tariff.

\subsection{Open-loop optimal control strategy}

The optimal operation of the pumps and valves in the proposed system by using open-loop optimal controller is shown in Figure 3 . The controller operates both potable and grey water pumps
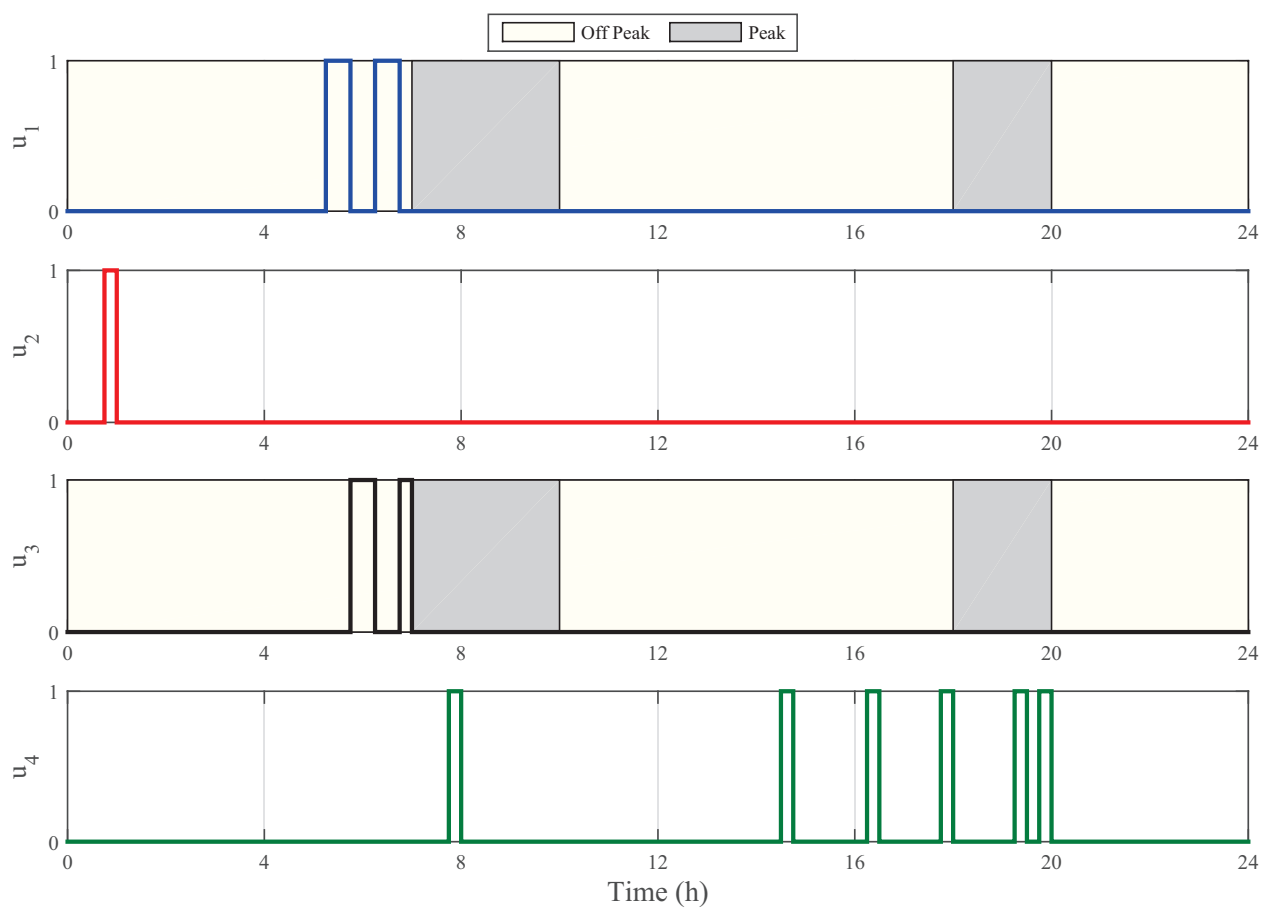

Figure 3: Optimal operation of pumps and valves by open-loop controller. 
during the off-peak period of the TOU tariff in meeting the household potable and grey water demand. This effectively shifts the electrical load to the period when the grid experiences less load, hence improving its stability. In addition, the controller switches both pumps only 2 times during the 24-h operating cycle in line with the objective seeking to minimize the maintenance cost of the pumps. This cost is attributed to frequent switching of a pump that causes wear and tear to its motor as it tries to overcome dead load (water) while changing from off to on status. In addition, the controller operates potable water valve once in early morning to supplement treated grey water. It also operates the drainage valve several times after predicting that collected water is no longer needed for treatment and pumping, and yet the holding tank has to be emptied within the operating cycle.

Optimal operation of the proposed system using the open-loop controller leads to variation of water level in various tanks as shown in Figure 4. The controller does not violate any con-

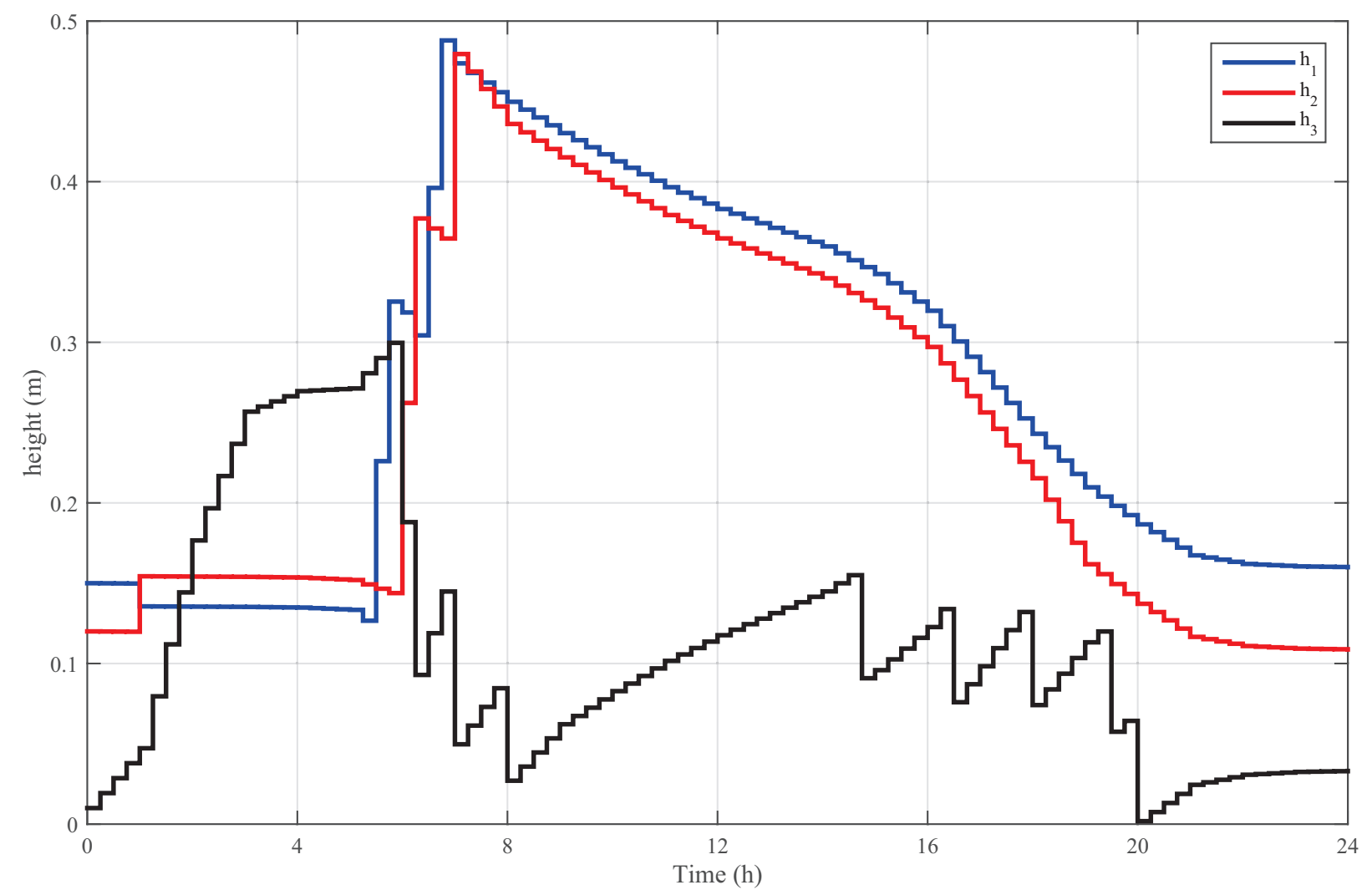

Figure 4: Variation of water level in respective tanks with open-loop controller.

straints in operating the system throughout the 24-h operating cycle. After a 15 minutes draw by potable water valve, the controller predicts that potable tank does not have sufficient water to take it through the high morning water demand, which coincides with peak TOU period. It, therefore, opts to switch on the pump twice at 05:15 and 06:15 for 30 minutes each, raising the level, $h_{1}$, to $0.49 \mathrm{~m}$, which is sufficient for the remaining period of the operating cycle. After this, water 
level $h_{1}$ keeps dropping while meeting potable water demand to a low of $0.16 \mathrm{~m}$ at the end of the operating cycle. At the onset, the holding tank is empty while the treated water level in the grey water tank is almost at the minimum allowable level. For this reason, the controller has to use potable water to meet grey water demand in the early morning leading to the potable water valve being switched on at 00:45 for 15 minutes. A simultaneous rise of water level in grey water tank and drop in potable water tank takes place during this time. As the day progresses, more water is collected hence there is no need for using potable water for non-potable uses. The controller predicts an increase in grey water demand in the morning hours, which again coincides with the peak TOU period. It consequently operates the grey water pump twice at 05:45 for 30 minutes and 06:45 for 15 minutes leading to a rise in level $h_{2}$ to $0.48 \mathrm{~m}$, which is sufficient to meet the grey water demand for the rest of the operating cycle. In addition, the pumping leads to a simultaneous drop in level $h_{3}$ to $0.05 \mathrm{~m}$. Since the controller predicts that the treated grey water is sufficient for the rest of the operating cycle, it then keeps draining the collected water to the drainage, and also ensures that the tank is emptied within the operating cycle to avoid formation bacteria responsible for foul smell.

\subsection{Closed-loop MPC strategy}

The closed-loop MPC strategy operates the proposed system by switching the pumps and valves as shown in Figure 5. Just like the open-loop controller, the closed-loop controller also
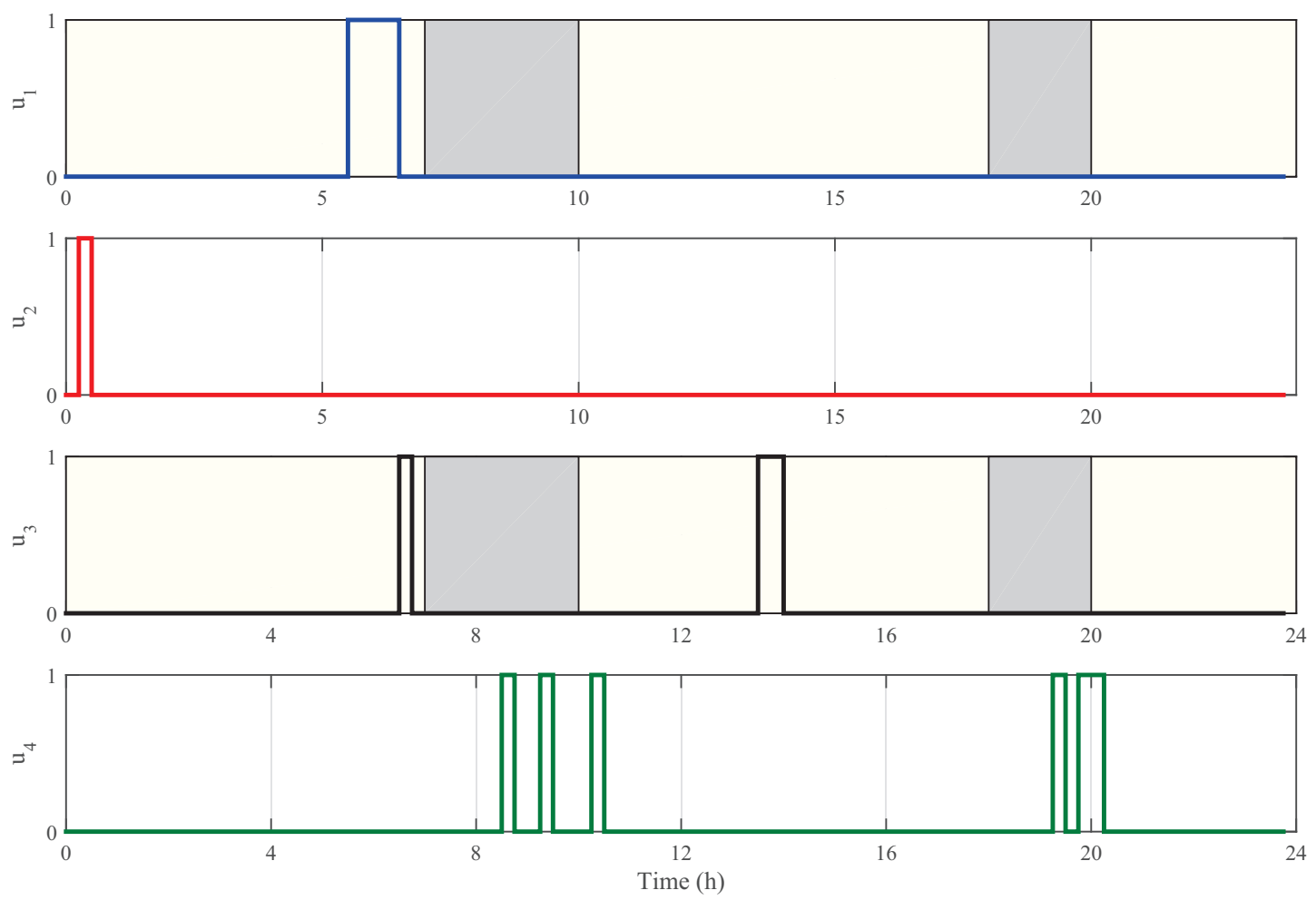

Figure 5: Optimal operation of pumps and valves using MPC strategy. 
operates both pumps during the cheaper off-peak TOU periods, in line with the utility's desire. Additionally, the closed-loop controller ensures that both pumps are not switched on frequently in order to minimize the maintenance cost. In predicting increasing potable water demand in the same period as the peak TOU period, the closed-loop controller switches the potable water pump once at 05:30 for 1 hour. This water is enough to meet potable water demand in the house for the remaining period of the operating cycle. In addition, the controller operates the grey water pump twice, first at $06: 30$ for 15 minutes and later at 13:30 for 30 minutes. However, the solenoid valves are switched on at any time since they use negligible amount of power. The controller switches the potable water valve early in the morning at 00:15 for 15 minutes when there is insufficient collected and treated grey water, and yet there is grey water demand to be met. It also switches the drainage valve frequently as more water is collected during the operating cycle to ensure the tank is emptied.

Optimal operation of the pumps and valves leads to variation of water levels in various tanks as shown in Figure 6. The closed-loop controller also ensures that none of the constraints is

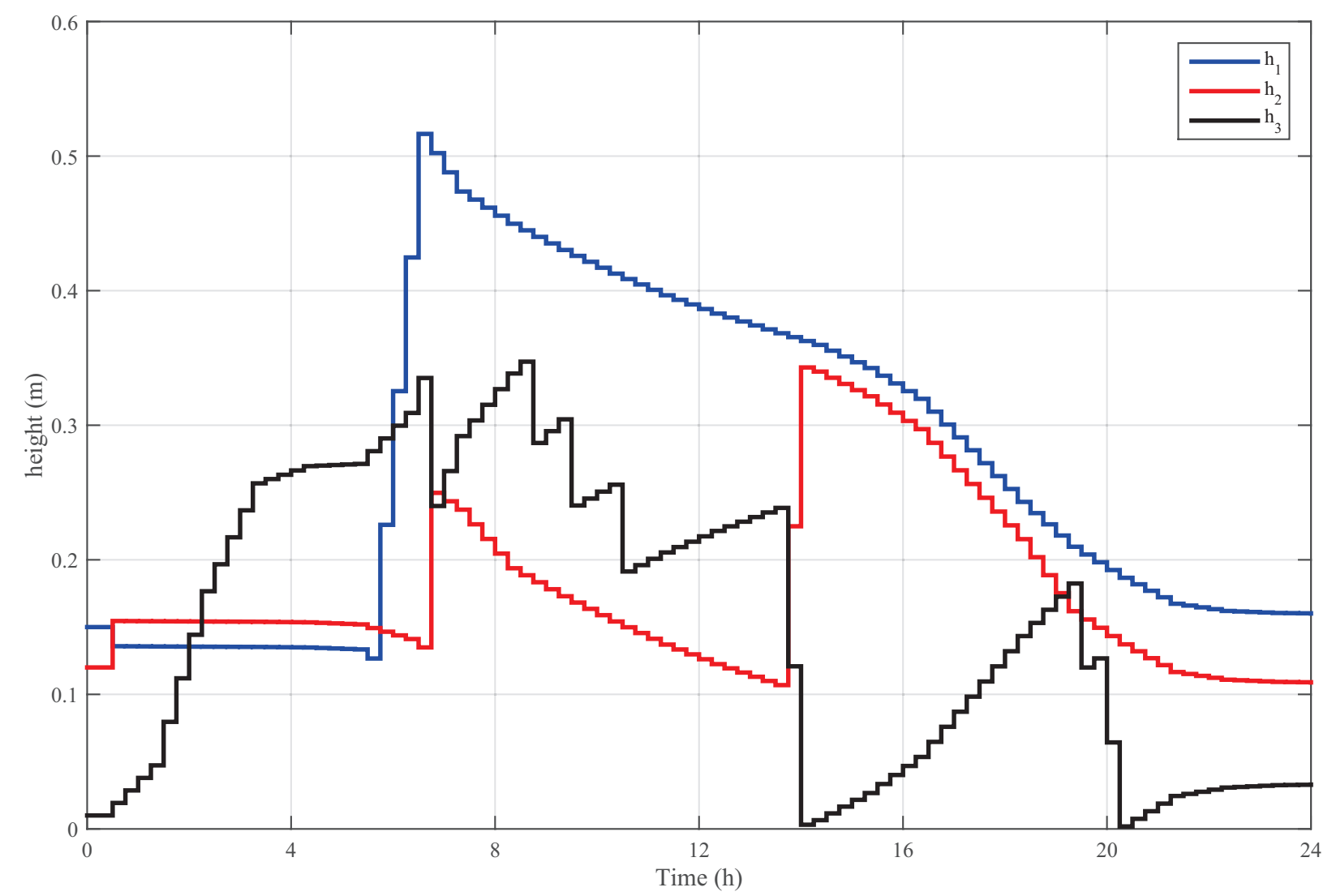

Figure 6: Variation of water level in respective tanks with MPC.

violated. Similar to the open-loop controller, the closed-loop controller predicts that the amount of stored potable water is not sufficient to meet the high potable water demand that coincides with 
the morning TOU peak. This situation is made worse, by insufficient collected and treated grey water in respective tanks forcing a 15 minute draw of potable water to meet grey water demand in the early morning. This prompts the controller to operate the potable water pump at 05:3006:30 raising the water level, $h_{1}$, to $0.52 \mathrm{~m}$, which is enough to meet potable water demand for the remaining period of the operating cycle. To meet the early morning grey water demand, the controller has to operate the potable water valve, $u_{2}$ for 15 minutes leading to a rise in level $h_{2}$ to $0.15 \mathrm{~m}$ and a simultaneous drop of $h_{1}$ to $0.14 \mathrm{~m}$. By morning hours, enough water has been collected in the morning even though the demand for grey water is increasing during the peak TOU period. Consequently, the controller pumps water from the holding tank at 06:30 raising the water level in the grey tank to $0.25 \mathrm{~m}$ while at the same time leading to a drop of water level in the holding tank to $0.24 \mathrm{~m}$. The treated grey water helps in meeting the morning water demand but unfortunately, it is not enough for the rest of the operating cycle. Therefore more water is treated and pumped to the grey tank at 13:30 for 30 minutes raising water level, $h_{2}$, to $0.34 \mathrm{~m}$ while also emptying the holding tank, as desired. Thereafter, the closed-loop controller predicts that the water in both storage tanks is sufficient to meet the demand for the remaining period of the operating cycle, hence, no more pumping is required. It therefore keeps operating the drainage valve and empties the tank again in the evening, in line with ensuring that the tank remains healthy and bacteria forms.

\subsection{Analysis and discussion}

The performance of the two optimal controllers is compared with the baseline, where potable water is used to meet all end uses in the house, over a period of one month. Table 3 shows the weekly water consumption, waste water discharge and the associated cost in the baseline and the proposed water recycling system operated using either control strategies. The consumption of water presented in the table holds for both scenarios with reliable and unreliable municipal water supply while the cost of water and waste water discharge is obtained using tariffs provided in section 4.3. Baseline and proposed strategies columns show the cumulative amount of potable water consumed and waste water discharged from the house together with their respective unit price. The weekday or weekend cumulative water is the amount of either potable or treated grey water used in the house at the end of 5 week days or 2 days of the weekend respectively. It is

Table 3: Comparison of weekly water consumption.

\begin{tabular}{ccllllllll}
\hline \multirow{2}{*}{ Wk } & \multirow{9}{*}{ Day } & $\begin{array}{l}\text { Potable } \\
\left(\mathrm{m}^{3}\right)\end{array}$ & $\begin{array}{l}\text { Cost } \\
\left(R / \mathrm{m}^{3}\right)\end{array}$ & $\begin{array}{l}\text { Waste } \\
\left(\mathrm{m}^{3}\right)\end{array}$ & $\begin{array}{l}\text { Cost } \\
\left(R / \mathrm{m}^{3}\right)\end{array}$ & $\begin{array}{l}\text { Potable } \\
\left(\mathrm{m}^{3}\right)\end{array}$ & $\begin{array}{l}\text { Proposed strategies } \\
\text { Cost } \\
\left(R / \mathrm{m}^{3}\right)\end{array}$ & $\begin{array}{l}\text { Waste } \\
\left(\mathrm{m}^{3}\right)\end{array}$ & $\begin{array}{l}\text { Cost } \\
\left(R / \mathrm{m}^{3}\right)\end{array}$ \\
\hline \multirow{2}{*}{1} & Weekday & 5.80 & 6.81 & 5.68 & 5.06 & 4.47 & 6.81 & 4.38 & 5.06 \\
& Weekend & 8.14 & 9.72 & 7.81 & 6.83 & 6.34 & 9.72 & 6.19 & 6.83 \\
\multirow{2}{*}{2} & Weekday & 13.94 & 12.77 & 12.89 & 8.81 & 10.81 & 9.72 & 10.21 & 6.83 \\
& Weekend & 16.29 & 12.77 & 14.65 & 8.81 & 12.68 & 12.77 & 11.79 & 8.81 \\
\multirow{2}{*}{3} & Weekday & 22.09 & 14.77 & 18.53 & 8.81 & 17.15 & 12.77 & 15.14 & 8.81 \\
& Weekend & 24.43 & 16.89 & 19.90 & 8.81 & 18.89 & 14.77 & 16.31 & 8.81 \\
\multirow{2}{*}{4} & Weekday & 30.23 & 18.25 & 22.82 & 8.81 & 23.31 & 14.77 & 18.97 & 8.81 \\
& Weekend & 31.61 & 18.25 & 25.98 & 8.81 & 24.18 & 16.89 & 19.47 & 8.81 \\
\hline
\end{tabular}


evident that more potable water is consumed in the baseline than when using the water recycling and harvesting system controlled by either control systems. Consequently, more waste water is discharged from the baseline than from the proposed system. As a result, the household ends up paying for potable water at a maximum unit cost $18.25 \mathrm{R} / \mathrm{m}^{3}$ in the baseline and as opposed to $16.89 \mathrm{R} / \mathrm{m}^{3}$ in the proposed strategies at the end of the month. Similarly, the household currently (baseline) pays for waste water at the maximum $8.81 \mathrm{R} / \mathrm{m}^{3}$ in a month from the second week while the proposed water conservation interventions would lead to the same happening from the weekend of the second week. Therefore, end users, whether with reliable or unreliable water supply, will have the added benefit of lower cost of potable and waste water in addition to conserving it. Operation of the proposed system by either control strategies consumes about $0.05 \mathrm{~m}^{3}$ and $0.13 \mathrm{~m}^{3}$ of potable water for grey uses in a week day and weekend, respectively, during the first two weeks as shown in Table 4. Thereafter, $0.05 \mathrm{~m}^{3}$ is used during the week day of the third week. Up to

Table 4: Weekly consumption by grey water end uses.

\begin{tabular}{cccccc}
\hline \multirow{2}{*}{ Wk } & & \multicolumn{2}{c}{ Potable water $\left(\mathrm{m}^{3}\right)$} & \multicolumn{2}{c}{ Treated water $\left(\mathrm{m}^{3}\right)$} \\
\hline \multirow{2}{*}{1} & Weekday & Open-loop & MPC & Open-loop & MPC \\
\cline { 3 - 6 } 2 & Weekend & 0.05 & 0.05 & 0.18 & 0.18 \\
2 & Weekday & 0.05 & 0.13 & 0.18 & 0.18 \\
& Weekend & 0.13 & 0.13 & 0.18 & 0.18 \\
\multirow{2}{*}{3} & Weekday & 0.05 & 0.05 & 0.18 & 0.18 \\
& Weekend & 0 & 0 & 0.26 & 0.18 \\
\multirow{2}{*}{4} & Weekday & 0 & 0 & 0.26 & 0.26 \\
& Weekend & 0 & 0 & 0.26 & 0.26 \\
\hline
\end{tabular}

this point, the cost of water has risen to $12.77 \mathrm{R} / \mathrm{m}^{3}$. Nonetheless, during the weekend of the third week, when the unit price rises to $14.77 \mathrm{R} / \mathrm{m}^{3}$, both controllers do not use potable water for grey end uses. This results from weight of the term responsible for minimizing the cost of water in objective functions (10) and (45) increasing significantly, making both controllers to give this term more preference as compared to the other terms. Further, the increasing weighting factor leads to an increase in the use of grey water from $0.18 \mathrm{~m}^{3}$ to $0.26 \mathrm{~m}^{3}$ for both controllers.

The monthly water and energy consumption, waste water discharge and the associated costs in the baseline and the two control strategies operating the water recycling and harvesting system are compared as shown in Table 5. If municipal water supply is reliable, the baseline water consumption is about $31.61 \mathrm{~m}^{3}$ leading to a discharge of about $25.98 \mathrm{~m}^{3}$ in a month. Therefore, the cost of both water supply and waste water discharge is about $589.69 \mathrm{R} /$ month, as there is no energy cost associated with pumping potable water for storage. Adoption of the proposed system in such a house would reduce the monthly potable water consumption and waste discharge by about $23.5 \%$ and $25.1 \%$ with the corresponding cost reduction of $32.3 \%$ and $29.5 \%$ respectively. Considering the proposed system would not pump potable water for storage, up to $30.8 \%$ cost savings can be achieved, irrespective of the added cost of energy incurred by the grey water pump. In the second scenario where potable water is pumped and stored, the baseline still uses $31.61 \mathrm{~m}^{3} /$ month of potable water, discharges about $25.98 \mathrm{~m}^{3} /$ month but at a higher cost of $604.02 \mathrm{R} /$ month, resulting 
Table 5: Proposed system's operating costs

\begin{tabular}{|c|c|c|c|}
\hline & Baseline & Open-loop & MPC \\
\hline \multicolumn{4}{|l|}{ Potable water } \\
\hline Amount $\left(m^{3} /\right.$ month $)$ & 31.61 & 24.18 & 24.18 \\
\hline Cost $(R /$ month $)$ & 395.15 & 267.46 & 267.46 \\
\hline \multicolumn{4}{|l|}{ Waste water } \\
\hline $\operatorname{Amount}\left(m^{3} /\right.$ month $)$ & 25.98 & 19.47 & 19.47 \\
\hline Cost $(R /$ month $)$ & 194.54 & 137.18 & 137.18 \\
\hline \multicolumn{4}{|l|}{ Potable pump } \\
\hline Energy $(k W h / m o n t h)$ & 13.04 & 8.00 & 8.00 \\
\hline Cost $(R /$ month $)$ & 14.33 & 5.84 & 5.84 \\
\hline \multicolumn{4}{|l|}{ Grey pump } \\
\hline $\operatorname{Energy}(k W h / m o n t h)$ & $0^{\mathrm{a}}$ & 3.25 & 3.25 \\
\hline Cost $(R /$ month $)$ & $0^{\mathrm{a}}$ & 3.37 & 3.37 \\
\hline Total cost $(R / \text { month })^{\mathrm{b}}$ & 604.02 & 413.85 & 413.85 \\
\hline
\end{tabular}

from cost of pumping potable water to the storage tank. Incorporation of the proposed system would still conserve about $23.5 \%$ potable water, reduce discharge by up to $25.1 \%$, corresponding to monthly cost saving from water and waste water of $32.3 \%$ and $29.5 \%$ respectively. In addition, the two controllers can save the cost of energy by up to $35.7 \%$ through shifting the load to the cheaper off-peak periods of the TOU tariff. Eventually, the proposed water recycling system with optimal control would save up to $31.5 \%$ of the total operation cost. This shows that the proposed system would conserve water, reduce waste water discharge and lead to economic benefits in both water supply scenarios.

Previous studies have shown that the two control strategies are known to adapt differently. Luo et al. (2015) hold that the closed-loop MPC is stable and robust in dealing with disturbances, unlike the open-loop controller which, as discused by Wanjiru et al. (2016b), can only deal with disturbances that do not largely change the demand pattern. This, however, comes at a higher cost in terms of computation and financial as well as more complexity, since it would require extra components to enable feedback of the height of water in the tanks to take place (Qi et al. (2015)). Adoption of either controller depends on the nature of each application. The open-loop controller is suitable where the demand pattern does not change significantly, otherwise the closed-loop MPC is suitable.

Collection of grey water is dependent on human behaviour making it a more reliable alternative source of water for non-potable end uses. On the other hand, raining is a natural occurrence making rain water harvesting largely dependent on climatic conditions and weather patterns. Since both rain water and grey water are collected to the same holding tank, rain water would have greatest impact early in the morning when the holding tank is almost empty. This would enable the two controllers to use this other than using potable water, and would lower the cost of operation even 
further. In countries with low amount of annual rainfall, like South Africa, grey water is a more reliable alternative source of water, and its amount hugely determines the design of the system. However, for regions with higher annual rainfall, the system design could be modified to maximize the efficiency of rain water. The potential of rain water harvesting in a year is estimated as a product of local precipitations, roof's catchment area and a non-dimensional runoff coefficient. This coefficient is important in accounting for losses arising due to spillage, leakage, wetting the surface and evaporation. It is therefore useful in predicting the amount of water running off the roof's surface and is conveyed to the storage system. Generally, sloping roofs have a higher coefficient than flat roofs (Farreny et al. (2011)). The two control systems can easily be modified for different types of roofs so as to accurately predict the amount of rain water that can be collected. Wide adoption of the system would greatly and positively influence the environment. The savings out of water conservation, waste water reduction and energy efficiency would immensely benefit municipal companies and energy utilities over a long time due to reduced demand for the two resources and sewerage services.

\subsection{Life cycle cost analysis}

It is necessary to evaluate the feasibility of implementing any project, not only in terms of environmental benefits, but also based on economic effect. The cost effectiveness of implementing this water recycling and harvesting system is based on comprehensive consideration of various cost and revenue components. One effective method is the present worth method that discounts back all future elements of the financial analysis of a project to their present worth, apart from capital costs that are already given in present terms. Thereafter, the positive and negative elements of the cash flow are summed, and if the net present value (NPV) is positive, then the investment is financially attractive (Vanek et al. (2012)). Life cycle cost (LCC) involves carrying out such analysis over the entire life of the project, and therefore has the benefit of capturing all costs and revenue that would take place during operation of the project. In this analysis, it is assumed that interest rate, taken as the inflation, revenue and operation cost are constant throughout the life of the project. Based on Capehart et al. (2006), costs included in analysis of LCC include cost of acquisition, operation, maintenance and disposal. Therefore,

$$
L C C=C_{c}+C_{o}+C_{s}
$$

where $C_{c}$ is the capital cost, $C_{o}$ is the operation cost and $C_{s}$ is the salvage cost at the end of life of the system. Capital cost includes total cost of acquiring and installing the system and labour. In the operation stage, the operation cost includes water, waste water, energy and maintenance cost incurred during the service life. Finally, salvage cost is the cost incurred at the end of system's life including the salvage value of the system, cost of removal and disposal (Bull (2015)). Equation (63) can be written in terms of the discounting factor, that is, the factor by which future cash flows must be multiplied with to get the present worth, as,

$$
L C C=C_{c}+\sum_{n=1}^{m} \frac{C_{o}(n)}{(1+r)^{n}}+C_{s},
$$

where $n$ and $m$ are the number of years and project lifetime respectively while $r$ is the discounting factor. The costs involved in this study are based on the South African market rates. Some 
assumptions are made while carrying out the life cycle cost analysis of the proposed system; the discounting factor is taken as South Africa's average inflation rate in 2016. The inflation rate, depreciation, operation and maintenance costs are assumed to be constant throughout the life of the system. The annualized cost and revenue are average from monthly values are obtained when the simulations are carried out over the four seasons in a year having varying demand for water. 
Table 6: Life cycle cost analysis of the water recycling and harvesting system.

\begin{tabular}{|c|c|c|c|c|c|c|c|c|c|c|}
\hline \multirow[b]{2}{*}{ Year } & & & \multirow{2}{*}{$\begin{array}{c}\text { Salvage } \\
\text { value }(\mathrm{R})\end{array}$} & \multicolumn{2}{|c|}{ Annual cost (R) } & \multirow{2}{*}{$\begin{array}{l}\text { Revenue } \\
\text { (R) }\end{array}$} & \multirow{2}{*}{$\begin{array}{l}\text { Total } \\
(\mathrm{R})\end{array}$} & \multirow{2}{*}{$\begin{array}{l}\text { Discounting } \\
\text { factor }\end{array}$} & \multicolumn{2}{|c|}{ Cash flows (R) } \\
\hline & \multicolumn{2}{|c|}{ Initial investment (R) } & & Operation & Maintenance & & & & Discounted & Cumulative \\
\hline & Water tanks & (3 500) & 1800 & & & & & & & \\
\hline & Pumps & $(280.00)$ & 50 & & & & & & & \\
\hline & UV purifier and & (4 500.00) & 1700 & & & & & & & \\
\hline 0 & & & & & & & & & & \\
\hline 0 & Controller & $(10000.00)$ & 500 & & & & & & & \\
\hline & Accessories & $(6000.00)$ & & & & & & & & \\
\hline & $\begin{array}{l}\text { Installation } \\
\text { cost }\end{array}$ & $(8000.00)$ & & & & & & & & \\
\hline & Total Capital & (28 230.00) & & & & & & 1.00 & (28 230.00) & (28 230.00) \\
\hline 1 & & & & $(4966.20)$ & $(200.00)$ & 2282.04 & $(2884.16)$ & 0.94 & $(2706.61)$ & (30 936.61) \\
\hline 2 & & & & (4 966.20) & $(200.00)$ & 2282.04 & $(2884.16)$ & 0.88 & (2 539.98) & (33 476.59) \\
\hline 3 & & & & (4 966.20) & $(200.00)$ & 2282.04 & (2 884.16) & 0.83 & (2 383.62) & (35 860.21) \\
\hline 4 & & & & (4 966.20) & $(200.00)$ & 2282.04 & $(2884.16)$ & 0.78 & (2 236.88) & (38 097.09) \\
\hline 5 & & & & (4 966.20) & $(200.00)$ & 2282.04 & $(2884.16)$ & 0.73 & (2 099.17) & (40 196.26) \\
\hline 6 & & & & (4 966.20) & $(200.00)$ & 2282.04 & (2 884.16) & 0.68 & (1 969.94) & (42 166.21) \\
\hline 7 & & & & (4 966.20) & $(200.00)$ & 2282.04 & $(2884.16)$ & 0.64 & (1 848.67) & (44 014.88) \\
\hline 9 & & & & (4 966.20) & $(200.00)$ & 2282.04 & $(2884.16)$ & 0.56 & (1 628.06) & (47 377.81) \\
\hline 10 & & & & (4 966.20) & $(200.00)$ & 2282.04 & (2 884.16) & 0.53 & (1 527.84) & (48 905.64) \\
\hline 11 & & & & (4 966.20) & $(200.00)$ & 2282.04 & (2 884.16) & 0.50 & (1 433.78) & (50 339.43) \\
\hline 12 & & & & (4 966.20) & $(200.00)$ & 2282.04 & (2 884.16) & 0.47 & (1 345.52) & $(51684.94)$ \\
\hline 13 & & & & (4 966.20) & $(200.00)$ & 2282.04 & (2 884.16) & 0.44 & (1 262.68) & (52 947.63) \\
\hline 14 & & & & (4 966.20) & $(200.00)$ & 2282.04 & (2 884.16) & 0.41 & (1 184.95) & (54 132.58) \\
\hline 15 & & & & (4 966.20) & $(200.00)$ & 2282.04 & (2 884.16) & 0.39 & (1 112.00) & (55 244.58) \\
\hline 16 & & & & (4 966.20) & $(200.00)$ & 2282.04 & (2 884.16) & 0.36 & (1 043.55$)$ & (56 288.13) \\
\hline 17 & & & & (4 966.20) & $(200.00)$ & 2282.04 & (2 884.16) & 0.34 & (979.30) & (57 267.43) \\
\hline 18 & & & & (4 966.20) & $(200.00)$ & 2282.04 & (2 884.16) & 0.32 & (919.02) & $(58$ 186.45) \\
\hline 19 & & & & (4 966.20) & $(200.00)$ & 2282.04 & (2 884.16) & 0.30 & (862.44) & (59 048.89) \\
\hline 20 & & & & (4 966.20) & (200.00) & 2282.04 & (2 884.16) & 0.28 & $(809.35)$ & (59 858.24) \\
\hline
\end{tabular}


Table 6 shows the life cycle cost analysis of the proposed system controlled using the MPC strategy. Expenses are indicated using negative values (brackets) while revenue is indicated as positive values. A discount factor of $6.56 \%$, which is the average inflation rate of South Africa for $2016^{4}$ is used to obtain the time value of money. In this analysis, all capital investment is taken to be done in the beginning of the project, and all components of the system will be operational for the 20 year life of the system. Further, cost of potable and waste water is assumed to remain constant for the entire life of the project. The discounted cash flows continuously increase the cumulative cash flows in each year, and the year which the cumulative cash flows becomes zero is an indicator of the break even point or the payback period. In this case, the proposed water recycling and harvesting system does not pay back in its 20 year life period, attributed to high capital cost coupled with low cost of water in South Africa, even though the country is semi arid. These findings are similar to a study done in two universities in South Africa by Ilemobade et al. (2013), as well as in other parts of the world such as Li et al. (2010) in Ireland, Fountoulakis et al. (2016) in Greece and Jabornig (2014) in Austria. A study by Adewumi et al. (2010) reveals that the current low water tariffs significantly influence end users' willingness to embrace water recycling. Government subsidies are therefore necessary in order to encourage the uptake of these technologies that will help in preventing water insecurity around the country and the region. Even though the proposed strategy currently looks economically infeasible, it is important to conduct a thorough analysis while considering full cost of water supply and waste water treatment.

South Africa is a semi-arid country that has constantly struggled to provide reliable water supply to the population. In the recent past, the situation has become worse forcing municipalities to implement water restriction in various parts of the nation!5. In addition, since the demand for water and energy is expected to keep growing as the population increases, their will keep increasing and the proposed system could soon become economically feasible. The implication of water scarcity and increased pressure on existing infrastructure is evident in the City of Cape Town ${ }^{6}$ where the municipality has opted to increase the cost of water and waste water in an effort to encourage efficient and sustainable use. The proposed water recycling and harvesting system is therefore an important intervention in ensuring reliable water supply, water conservation and energy efficiency are achieved.

\section{Conclusion}

Water and energy, two inseparable resources, are vital for sustainable economic development of any country. Supply of these resources is however unreliable in South Africa due to various factors such as climatic factors, population increase, improved standards of living and rapid urbanization. This has led in increased demand surpassing existing supply capacity and various demand management strategies are required. Grey water recycling and rain water harvesting are suitable for conserving water by providing alternative sources hence reducing the demand for water and waste water services from the municipalities. Two controllers are designed in this study

\footnotetext{
${ }^{4}$ www.inflation.eu/inflation-rates/south-africa/historic-inflation/ cpi-inflation-south-africa-2016.aspx

5 www.droughtsa.org.za/about-the-drought/water-restrictions.html

${ }^{6}$ https://www.westerncape.gov.za/general-publication/how-manage-water-restrictions-your-home
} 
to optimally operate the grey water and rain water recycling system for a house subject to the TOU electricity tariff in South Africa, where a case was considered. The two controllers perform the same, however, the open-loop controller is easier and more cost effective to implement while the closed-loop MPC is more robust and reliable in controlling the proposed system in domestic houses. The proposed system can potentially reduce potable water consumption by $23.5 \%$ and consequent waste water discharge by $25.1 \%$ as compared to the baseline. Optimal operation of the system using either controllers can reduce the cost of energy by $35.7 \%$ through load shifting. For the two scenarios considered in this study, that is reliable and unreliable municipal water supply, optimal operation of the proposed system can lead to a total operation cost saving of up to $30.8 \%$ and $31.5 \%$ respectively. Despite the proposed system having the benefit to conserve water and efficiently use energy, it does not pay back the cost within its lifetime. Importantly, studies in other parts of the world have shown similar results, predicting that the worsening water insecurity due to increased demand and climate change could make such systems financially feasible in the near future. Governments should encourage adoption of these systems in order to conserve water and environment at large. This can be done through policies, regulations, subsidies and incentives to encourage their uptake especially in cities with functional centralized water and waste water systems. Otherwise, there will be no motivation for building developers and owners to consider these important systems. In cities with dysfunctional or non-existent centralized water supply and waste water systems such as Nairobi in Kenya, Jakarta in Indonesia and Lima in Peru, building owners rely on exorbitantly expensive water vendors to augment water supply and septic tanks for sanitation. Considering these cities are rapidly expanding, the demand for housing requiring water and sanitation infrastructure will keep increasing. It is therefore prudent for authorities in such countries to develop proper and acceptable policies that would increase water and sanitation security. The decentralized system developed in this paper is necessary and comes as a huge relief in increasing reliability and security of water supply at lower cost. Better still, less water would go down the drain taking a longer period before the septic tank requires emptying. More studies could be carried out in these areas to determine the economic feasibility. The system can be incorporated in new building designs or retrofitted in existing ones, which would be more expensive. The complexity of retrofitting would, however, depend on the plumbing system and space available. Wide adoption of the system would have huge benefit to the environment and municipalities that would not require to rapidly expand their existing supply and drainage infrastructure. This study forms the basis for future research into optimal operation of grey water recycling and rain water harvesting systems in the built sector, whether domestic or commercial, to enhance resources conservation and efficiency.

\section{Acknowledgements}

The authors would like to thank the National Hub for Energy Efficiency and Demand Side Management (EEDSM) for supporting this research.

\section{References}

Adewumi, J., Ilemobade, A., Van Zyl, J., 2010. Treated wastewater reuse in South Africa: Overview, potential and challenges. Resources, Conservation and Recycling 55, 221-231. 
Al-Jayyousi, O.R., 2003. Greywater reuse: towards sustainable water management. Desalination 156, 181-192.

Badenhorst, W., Zhang, J., Xia, X., 2011. Optimal hoist scheduling of a deep level mine twin rock winder system for demand side management. Electric Power Systems Research 81, 1088-1095.

Bohensky, E.L., 2006. A social-ecological systems perspective on water management in South Africa. Ph.D. thesis. University of Pretoria.

Brandoni, C., Bošnjaković, B., 2017. HOMER analysis of the water and renewable energy nexus for water-stressed urban areas in Sub-Saharan Africa. Journal of Cleaner Production 155, 105-118.

Bull, J.W., 2015. Life Cycle Costing: For the Analysis, Management and Maintenance of Civil Engineering Infrastructure. Illustrated ed., Whittles Publishing.

Capehart, B.L., Turner, W.C., Kennedy, W.J., 2006. Guide to energy management. The Fairmont Press, Inc.

Chatterjee, A., Zhang, L., Xia, X., 2015. Optimization of mine ventilation fan speeds according to ventilation on demand and time of use tariff. Applied Energy 146, 65-73.

Chou, M., Xia, X., 2007. Optimal cruise control of heavy-haul trains equipped with electronically controlled pneumatic brake systems. Control Engineering Practice 15, 511-519.

Cobbinah, P.B., Erdiaw-Kwasie, M.O., Amoateng, P., 2015. Africas urbanisation: Implications for sustainable development. Cities 47, 62-72.

Elaiw, A., Xia, X., Shehata, A., 2012. Application of model predictive control to optimal dynamic dispatch of generation with emission limitations. Electric Power Systems Research 84, 31-44.

Fan, Y., Xia, X., 2017. A multi-objective optimization model for energy-efficiency building envelope retrofitting plan with rooftop pv system installation and maintenance. Applied Energy 189, 327-335.

Farreny, R., Morales-Pinzón, T., Guisasola, A., Taya, C., Rieradevall, J., Gabarrell, X., 2011. Roof selection for rainwater harvesting: quantity and quality assessments in Spain. Water Research 45, 3245-3254.

Fountoulakis, M., Markakis, N., Petousi, I., Manios, T., 2016. Single house on-site grey water treatment using a submerged membrane bioreactor for toilet flushing. Science of the Total Environment 551, 706-711.

Ghisi, E., de Oliveira, S.M., 2007. Potential for potable water savings by combining the use of rainwater and greywater in houses in southern Brazil. Building and Environment 42, 1731-1742.

Hoy, L.H., 2009. A proactive water supply shortage response plan focusing on the Green Industry in the Rand Water supply area. Ph.D. thesis. University of South Africa.

Ilemobade, A., Olanrewaju, O., Griffioen, M., 2013. Greywater reuse for toilet flushing at a university academic and residential building. Water SA 39, 351-360.

Jabornig, S., 2014. Overview and feasibility of advanced grey water treatment systems for single households. Urban Water Journal 11, 361-369.

Kahinda, J.M., Taigbenu, A., 2011. Rainwater harvesting in South Africa: Challenges and opportunities. Physics and Chemistry of the Earth, Parts A/B/C 36, 968 - 976.

Kim, R.H., Lee, S., Jeong, J., Lee, J.H., Kim, Y.K., 2007. Reuse of greywater and rainwater using fiber filter media and metal membrane. Desalination 202, 326-332.

Kirk, D.E., 2012. Optimal Control Theory: An Introduction. Dover Publications Inc., New York, U.S.A.

Kozák, Š., 2016. From PID to MPC: Control engineering methods development and applications, in: Cybernetics Informatics (K\& I), Levoča, Slovakia, pp. 1-7.

Lam, L., Kurisu, K., Hanaki, K., 2015. Comparative environmental impacts of source-separation systems for domestic wastewater management in rural china. Journal of Cleaner Production 104, 185-198.

Li, Z., Boyle, F., Reynolds, A., 2010. Rainwater harvesting and greywater treatment systems for domestic application in Ireland. Desalination 260, 1-8.

Lipták, B.G., 2005. Instrument Engineers' Handbook: Process Control and Optimization. volume 2. CRC Press.

Loux, J., Winer-Skonovd, R., Gellerman, E., 2012. Evaluation of combined rainwater and greywater systems for multiple development types in mediterranean climates. Journal of Water Sustainability 2, 55-77.

Luo, J., Huang, W., Zhang, S., 2015. Energy cost optimal operation of belt conveyors using model predictive control methodology. Journal of Cleaner Production 105, 196-205.

Malatji, E.M., Zhang, J., Xia, X., 2013. A multiple objective optimisation model for building energy efficiency investment decision. Energy and Buildings 61, 81-87.

Mathaba, T., Xia, X., 2015. A parametric energy model for energy management of long belt conveyors. Energies 8 , 
$13590-13608$.

Mathaba, T., Xia, X., Zhang, J., 2014. Analysing the economic benefit of electricity price forecast in industrial load scheduling. Electric Power Systems Research 116, 158 - 165.

Mayne, D.Q., Rawlings, J.B., Rao, C.V., Scokaert, P.O., 2000. Constrained model predictive control: Stability and optimality. Automatica 36, 789-814.

Middelberg, A., Zhang, J., Xia, X., 2009. An optimal control model for load shifting-with application in the energy management of a colliery. Applied Energy 86, 1266-1273.

Morales-Pinzón, T., Rieradevall, J., Gasol, C.M., Gabarrell, X., 2015. Modelling for economic cost and environmental analysis of rainwater harvesting systems. Journal of Cleaner Production 87, 613-626.

Ntsaluba, S., Zhu, B., Xia, X., 2016. Optimal flow control of a forced circulation solar water heating system with energy storage units and connecting pipes. Renewable Energy 89, 108-124.

Numbi, B., Xia, X., 2015. Systems optimization model for energy management of a parallel HPGR crushing process. Applied Energy 149, 133 - 147.

Numbi, B., Xia, X., 2016. Optimal energy control of a crushing process based on vertical shaft impactor. Applied Energy 162, 1653-1661.

Odhiambo, N.M., 2009. Electricity consumption and economic growth in South Africa: A trivariate causality test. Energy Economics 31, 635-640.

Qi, R., Mei, H., Chen, C., Qian, F., 2015. A fast MPC algorithm for reducing computation burden of MIMO. Chinese Journal of Chemical Engineering 23, 2087-2091.

Roy, S.S., Rouault, M., 2013. Spatial patterns of seasonal scale trends in extreme hourly precipitation in South Africa. Applied Geography 39, 151-157.

Rozos, E., Makropoulos, C., Butler, D., 2009. Design robustness of local water-recycling schemes. Journal of Water Resources Planning and Management 136, 531-538.

Setlhaolo, D., Xia, X., 2015. Optimal scheduling of household appliances with a battery storage system and coordination. Energy and Buildings 94, 61-70.

Setlhaolo, D., Xia, X., 2016. Combined residential demand side management strategies with coordination and economic analysis. International Journal of Electrical Power \& Energy Systems 79, 150-160.

Sichilalu, S., Mathaba, T., Xia, X., 2017. Optimal control of a wind-pv-hybrid powered heat pump water heater. Applied Energy 185, 1173-1184.

Sichilalu, S.M., Xia, X., 2015. Optimal power dispatch of a grid tied-battery-photovoltaic system supplying heat pump water heaters. Energy Conversion and Management 102, 81-91.

Stec, A., Kordana, S., Słyś, D., 2017. Analysing the financial efficiency of use of water and energy saving systems in single-family homes. Journal of Cleaner Production 151, 193-205.

Stillwell, A.S., King, C.W., Webber, M.E., Duncan, I.J., Hardberger, A., 2010. The energy-water nexus in Texas. Ecology and Society , 1-20.

Tazvinga, H., Xia, X., Zhang, J., 2013. Minimum cost solution of photovoltaic-diesel-battery hybrid power systems for remote consumers. Solar Energy 96, 292-299.

Tazvinga, H., Zhu, B., Xia, X., 2014. Energy dispatch strategy for a photovoltaic-wind-diesel-battery hybrid power system. Solar Energy 108, 412-420.

Tazvinga, H., Zhu, B., Xia, X., 2015. Optimal power flow management for distributed energy resources with batteries. Energy Conversion and Management 102, 104-110.

Tóth, L.R., Nagy, L., Szeifert, F., 2012. Similarities of model predictive control and constrained direct inverse. Intelligent Control and Automation 3, 278.

Vanek, F.M., Albright, L.D., Angenent, L.T., 2012. Energy Systems Engineering: Evaluation and Implementation. McGraw-Hill Professional. chapter Economic Analysis of Energy Projects and Systems. pp. 120-190.

Wang, B., Xia, X., Zhang, J., 2014. A multi-objective optimization model for the life-cycle cost analysis and retrofitting planning of buildings. Energy and Buildings 77, 227-235.

Wang, L., 2009. Model predictive control system design and implementation using MATLABß. Springer Science \& Business Media.

Wanjiru, E., Sichilalu, S., Xia, X., 2017a. Optimal operation of integrated heat pump-instant water heaters with renewable energy. Energy Procedia 105, 2151-2156. 
Wanjiru, E., Xia, X., 2017. Optimal energy-water management in urban residential buildings through grey water recycling. Sustainable Cities and Society 32, 654-668.

Wanjiru, E.M., Sichilalu, S.M., Xia, X., 2016a. Optimal integrated diesel grid-renewable energy system for hot water devices. Energy Procedia 103, 117-122.

Wanjiru, E.M., Sichilalu, S.M., Xia, X., 2017b. Model predictive control of heat pump water heater-instantaneous shower powered with integrated renewable-grid energy systems. Applied Energy https://doi.org/10.1016/j.apenergy.2017.05.033.

Wanjiru, E.M., Sichilalu, S.M., Xia, X., 2017c. Optimal control of heat pump water heater-instantaneous shower using integrated renewable-grid energy systems. Applied Energy 201, 332-342.

Wanjiru, E.M., Xia, X., 2015. Energy-water optimization model incorporating rooftop water harvesting for lawn irrigation. Applied Energy 160, 521-531.

Wanjiru, E.M., Zhang, L., Xia, X., 2016b. Model predictive control strategy of energy-water management in urban households. Applied Energy 179, 821-831.

Xia, X., Zhang, J., 2015. Operation efficiency optimisation modelling and application of model predictive control. IEEE/CAA Journal of Automatica Sinica 2, 166-172.

Xia, X., Zhang, L., 2016. Industrial energy systems in view of energy efficiency and operation control. Annual Reviews in Control 42, 299-308.

Zhang, D., Gersberg, R.M., Wilhelm, C., Voigt, M., 2009. Decentralized water management: rainwater harvesting and greywater reuse in an urban area of Beijing, China. Urban Water Journal 6, 375-385.

Zhang, H., Xia, X., Zhang, J., 2012. Optimal sizing and operation of pumping systems to achieve energy efficiency and load shifting. Electric Power Systems Research 86, 41-50.

Zhang, J., Xia, X., 2011. A model predictive control approach to the periodic implementation of the solutions of the optimal dynamic resource allocation problem. Automatica 47, 358-362.

Zhang, L., Xia, X., Zhang, J., 2014. Improving energy efficiency of cyclone circuits in coal beneficiation plants by pump-storage systems. Applied Energy 119, 306 - 313.

Zhuan, X., Xia, X., 2013. Optimal operation scheduling of a pumping station with multiple pumps. Applied Energy $104,250-257$. 